\title{
Dexamethasone Regulates EphA5, a Potential Inhibitory Factor with Osteogenic Capability of Human Bone Marrow Stromal Cells
}

\author{
Tsuyoshi Yamada, ${ }^{1,2}$ Toshitaka Yoshii, ${ }^{1}$ Hiroaki Yasuda, ${ }^{1}$ \\ Atsushi Okawa, ${ }^{1,2}$ and Shinichi Sotome ${ }^{3}$ \\ ${ }^{1}$ Department of Orthopaedic and Spinal Surgery, Graduate School, Tokyo Medical and Dental University, Tokyo 113-8510, Japan \\ ${ }^{2}$ Global Center of Excellence (GCOE) Program, International Research Center for Molecular Science in Tooth and Bone Diseases, \\ Tokyo Medical and Dental University, Tokyo 113-8510, Japan \\ ${ }^{3}$ Section of Regenerative Therapeutics for Spine and Spinal Cord, Tokyo Medical and Dental University, Tokyo 113-8510, Japan \\ Correspondence should be addressed to Shinichi Sotome; sotome.orth@tmd.ac.jp
}

Received 13 June 2015; Revised 30 November 2015; Accepted 3 December 2015

Academic Editor: Luca Vanella

Copyright (C) 2016 Tsuyoshi Yamada et al. This is an open access article distributed under the Creative Commons Attribution License, which permits unrestricted use, distribution, and reproduction in any medium, provided the original work is properly cited.

\begin{abstract}
We previously demonstrated the importance of quality management procedures for the handling of human bone marrow stromal cells (hBMSCs) and provided evidence for the existence of osteogenic inhibitor molecules in BMSCs. One candidate inhibitor is the ephrin type-A receptor 5 (EphA5), which is expressed in hBMSCs and upregulated during long-term culture. In this study, forced expression of EphA5 diminished the expression of osteoblast phenotypic markers. Downregulation of endogenous EphA5 by dexamethasone treatment promoted osteoblast marker expression. EphA5 could be involved in the normal growth regulation of BMSCs and could be a potential marker for replicative senescence. Although Eph forward signaling stimulated by ephrin-B-Fc promoted the expression of ALP mRNA in BMSCs, exogenous addition of EphA5-Fc did not affect the ALP level. The mechanism underlying the silencing of EphA5 in early cultures remains unclear. EphA5 promoter was barely methylated in hBMSCs while histone deacetylation could partially suppress EphA5 expression in early-passage cultures. In repeatedly passaged cultures, the upregulation of EphA5 independent of methylation could competitively inhibit osteogenic signal transduction pathways such as EphB forward signaling. Elucidation of the potential inhibitory function of EphA5 in hBMSCs may provide an alternative approach for lineage differentiation in cell therapy strategies and regenerative medicine.
\end{abstract}

\section{Introduction}

Human bone marrow stromal cells (hBMSCs) are an attractive source for bone tissue engineering applications because of their proliferative capacity and multipotency $[1,2]$. However, their differentiation potential deteriorates over multiple cell divisions [3-5], and it may thus be difficult to obtain a sufficient number of effective cells for clinical applications through ex vivo expansion. Thus, the clinical application of BMSCs requires a more complete understanding of the mechanisms that lead to the senescence of these cells.

Our previous study revealed that long-term passaged BMSCs are capable of forming bone but can also inhibit bone formation. In particular, we demonstrated the importance of quality management procedures for the handling of hBMSCs and provided evidence for the existence of osteogenic inhibitor molecules in BMSCs. One candidate inhibitor is the ephrin type-A receptor 5 (EphA5), which is expressed at low levels at early passages of hBMSC primary culture and upregulated during long-term culture [5]. EphA5 is a member of the ephrin receptor tyrosine kinase subfamily and can bind ephrins A1, A2, A3, A4, and A5. The ephrin receptors are divided into 2 groups based on the similarity of their extracellular domain sequences and their affinities for binding ephrin-A and ephrin-B ligands. The ephrin receptors have the ability to induce both forward and reverse (bidirectional) signaling between adjacent interacting cells. Recently, ephrins and their receptors were reported to be involved in 
bone metabolism. Zhao et al. demonstrated that signaling between the extracellular domains of ephrin-B2 expressed on osteoclasts and EphB4 in osteoblasts suppresses osteoclast differentiation and stimulates osteogenic differentiation [6]. In addition to osteoclast-osteoblast interactions, osteoblastosteoblast interactions through ephrin A2 and either EphA2 or EphA4 have also been shown to occur $[7,8]$. We found that downregulation of endogenous EphA5 using specific siRNAs or dexamethasone (DEX) treatment promoted osteoblast marker expression, suggesting that EphA5 is a potential inhibitor of bone formation [5]. However, there have been no reports on the role of EphA5 in bone metabolism, and the mechanism underlying the inhibitory effect of EphA5 on the osteogenic differentiation of BMSCs remains unclear.

BMSCs are heterogeneous and contain subpopulations of osteoprogenitors and undifferentiated cells, and it is difficult to assess the overall expression profile of each batch of cells in a clinical setting [9]. DEX, which has been used to differentiate BMSCs into adipogenic [1], chondrogenic [10$12]$, and osteogenic lineages [10, 13], affects not only the proliferation rate but also the subpopulation composition of BMSCs. However, the precise mechanism of how DEX induces differentiation is still unclear. Previously, we hypothesized that DEX does not directly induce BMSCs into specific lineages but rather augments the responsiveness of BMSCs to other differentiation reagents applied together with DEX. We reported that DEX induced selective proliferation of cells with higher differentiation capability not only during the initial proliferation culture but also during subsequent osteogenic induction [14] and that cells that had higher responsiveness to BMP stimulation selectively proliferated under continuous DEX treatment [15]. Moreover, DEX treatment selectively suppressed EphA5 expression [5]. Therefore, EphA5 may be a potential negative prognostic indicator of the responsiveness of BMSCs to differentiation reagents, and it may be involved in the senescence or reduced differentiation potency of BMSCs.

The goals of our research were to determine the effects of EphA5 on BMSC quality and to clarify the inhibitory mechanism involved in the reduction of differentiation potential after repeated cell division. Here, we demonstrated the inhibitory effects of EphA5 on osteogenic differentiation in hBMSCs and investigated its function and mechanism of action, together with the association between EphA5 and DEX treatment. Our findings suggest that EphA5 may be a new therapeutic target and quality control marker for the osteogenic differentiation capability of hBMSCs.

\section{Material and Method}

All of the experiments in this study were specifically approved by the Review Board of the Tokyo Medical and Dental University and were performed in accordance with the Declaration of Helsinki and university guidelines for the care and use of human subjects. Participants provided their written informed consent to participate in this study.

2.1. Primary Culture of hBMSCs. After informed consent was obtained, BMSCs were cultured from bone marrow aspirates of 34 patients who had received hip surgery at Tokyo Medical and Dental University under a protocol that was approved by the institutional review board. The donors ranged in age from 30 to 87 years. Approximately $2 \mathrm{~mL}$ of bone marrow aspirate was obtained from the medullary cavity of the femoral shaft of each patient using a bone marrow biopsy needle (Cardinal Health, Dublin, OH, USA). The aspirate was added to $20 \mathrm{~mL}$ of growth medium [Dulbecco's modified Eagle medium (DMEM), Sigma-Aldrich Co., St. Louis, MO, USA] containing $10 \%$ fetal bovine serum (Life Technologies Co., Carlsbad, CA, USA) and 1\% antibiotic-antimycotic $(10,000 \mathrm{U} / \mathrm{mL}$ penicillin G sodium, $10,000 \mu \mathrm{g} / \mathrm{mL}$ streptomycin sulfate, and $25 \mu \mathrm{g} / \mathrm{mL}$ amphotericin B; Life Technologies) that contained 200 IU of sodium heparin (Mochida Pharmaceutical Co. Ltd., Tokyo, Japan) and then centrifuged to remove the fat layer. Bone marrow cells were then resuspended in growth medium, and aliquots of the cell suspensions were used to count nucleated cells after hemolysis. Subsequently, $1 \times 10^{8}$ nucleated bone marrow cells were plated into two $225 \mathrm{~cm}^{2}$ flasks (Becton, Dickinson and Company, Franklin Lakes, NJ, USA). The cells were then cultured in each medium at $37^{\circ} \mathrm{C}$ in a humidified atmosphere containing 95\% air and 5\% $\mathrm{CO}_{2}$, and the medium was replaced every three days. When primary cultures became nearly confluent, the cells were detached with $0.25 \%$ trypsin containing $1 \mathrm{mM}$ EDTA (Life Technologies) and subsequently replated for each assay. Cells were passaged at a density of $2 \times 10^{3}$ cells $/ \mathrm{cm}^{2}$, and hBMSCs at passages 1 (P1), P5, and P10 were stored in liquid nitrogen until further use. The collected hBMSCs were either cultured or preserved separately; the cells from individual donors were assayed independently to prevent cross contamination of hBMSCs from different donors.

2.2. Osteogenic Differentiation. BMSCs were replated at $2 \times$ $10^{3}$ cells $/ \mathrm{cm}^{2}$ in a six-well culture plate. When the culture plates became $80 \%$ confluent, the culture media of each group were changed to osteogenic media containing $10 \mathrm{mM} \beta$ glycerophosphate ( $\beta$-GP, Sigma-Aldrich Co.) and $50 \mu \mathrm{g} / \mathrm{mL}$ ascorbic acid phosphate (AA, Wako, Osaka, Japan) [13] with or without $100 \mathrm{nM}$ dexamethasone (DEX, Life Technologies) and/or BMP-2. After zero and seven days of osteogenic culture, the cells were used in each assay.

2.3. RNA Isolation, Real-Time RT-PCR. Total RNA was isolated from the culture dishes using RNeasy Mini Kits (Qiagen, GmbH, Hilden, Germany), and first-strand cDNA was prepared using the PrimeScript RT Reagent Kit with gDNA Eraser (Takara Bio Inc., Shiga, Japan) according to the manufacturer's instructions. Gene expression was quantified by real-time polymerase chain reaction (PCR) using the Mx3000P QPCR System (Agilent Technologies, Inc., Santa Clara, CA, USA) and GoTaq qPCR Master Mix (Promega Co., Fitchburg, WI, USA). Primer sets were predesigned and purchased from Takara Bio Inc. (Table 1). Standards were generated from one specific sample, and every PCR reaction in this study was run with a standard curve to quantify the relative $\mathrm{Ct}$ values of the samples. $\beta$-actin was used to normalize the amount of template that was present in each sample. 
TABLE 1: RT-PCR primers used in this study.

\begin{tabular}{|c|c|c|}
\hline Genes & Forward & Reverse \\
\hline$\beta$-act & TGGCACCCAGCACAATGAA & CTAAGTCATAGTCCGCCTAGAAGCA \\
\hline ALP & GGACCATTCCCACGTCT & CCTTGTAGCCAGGCCCATTG \\
\hline Runx2 & CACTGGCGCTGCAACAAGA & CATTCCGGAGCTCAGCAGAATA \\
\hline ephrin-A1 & TGATCGCCACACCGTCTTC & CAGCGTCTGCCACAGAGTGA \\
\hline ephrin-A2 & CTGCCTGCGACTGAAGGTGTA & ACACGAGTTATTGCTGGTGAAGATG \\
\hline ephrin-A3 & TCTGAGGATGAAGGTGTTCGTCTG & TTCTCAAGCTTGGGCACCTG \\
\hline ephrin-A4 & TCGGCTTTGAGTTCTTACCTGGA & AGACACCTGGAGCCTCAAGCA \\
\hline ephrin-A5 & TGCTGGCATGTCGGAGGTTA & ACTGCAAAGCAGGGCAGTACAAG \\
\hline ephrin-B1 & CCAAGAACCTGGAGCCCGTA & AGATGATGTCCAGCTTGTCTCCAAT \\
\hline ephrin-B2 & CTGCTGGATCAACCAGGAATAAAGA & TCCTGAAGCAATCCCTGCAAATA \\
\hline ephrin-B3 & CTGTCTACTGGAACTCGGCGAATAA & CCGATCTGAGGGTACAGCACATAA \\
\hline EphA1 & CCTGTGCTGCAAGGTGTCTGA & GTGAAGATCCGATGGGCAATG \\
\hline EphA2 & GAGCTTTGGCATTGTCATGTGG & GCACTGCATCATGAGCTGGTAGA \\
\hline EphA3 & TTTGTCCTGGCAAGAACCTGAAC & TTCGGGCTCGGATTTGGA \\
\hline EphA4 & GCCGAGTGAGCTCCAATGCTA & GCCTGCATACACAAGGTGAAGCTA \\
\hline EphA5 & GCCCGGCAGTATGTGTCTGTAA & TCCATTGGGACGATCTGGTTC \\
\hline EphA7 & AGAACACTGTCCTCACACTTGACC & TGACAAGCATAAACCACCAGTTCTA \\
\hline EphA8 & CCTATGGAAGTCGGAAACATGGTC & AGAGCCCAGAAATTGGGTAAGAGTG \\
\hline EphB1 & GCCCAATGGCATCATCCTG & ATCAATCCTTGCTGTGTTGGTCTG \\
\hline EphB2 & GACCAAGAGCACACCTGTGATGA & CCACCAGCTGGATGACTGTGA \\
\hline EphB3 & AGACTCGGACTCTGCGGACA & GCTCACTCCACTCGAGGATCA \\
\hline EphB4 & ATGCCTGGAGTTACGGGATTG & TCCAGCATGAGCTGGTGGAG \\
\hline EphB6 & GACCAATGGGAACATCCTGGAC & CCCGCACCTGGAAACCATAG \\
\hline
\end{tabular}

2.4. Lentivirus Production and Transduction. Lentivirus production was performed using the GeneCopoeia HIV-Based Lentiviral Expression System (GeneCopoeia, Inc., MD, USA): $1.3 \times 10^{6}$ GeneCopoeia 293Ta lentiviral packaging cells were plated in a $10 \mathrm{~cm}$ cell culture dish (Greiner Bio-One, Frickenhausen, Germany, Cat. number 664-960) in $10 \mathrm{~mL}$ of DMEM supplemented with $10 \%$ heat-inactivated fetal bovine serum and incubated at $37^{\circ} \mathrm{C}$ with $5 \% \mathrm{CO}_{2}$ for 24 hours before transfection.

In a sterile polypropylene tube, we diluted $2.5 \mu \mathrm{g}$ of lentiviral ORF expression vector plasmid (GeneCopoeia) (Figure 1(a)), $1.25 \mu \mathrm{g}$ of packaging plasmid, pCAG-HIVgp (a gift from Dr. Miyoshi, RIKEN), and $1.25 \mu \mathrm{g}$ of VSV-G, Rev plasmid, and pCMV-VSV-G-RSV-Rev (a gift from Dr. Miyoshi, RIKEN) into $200 \mu \mathrm{L}$ of Opti-MEM 1 (Invitrogen). In a separate tube, we diluted $15 \mu \mathrm{L}$ of FuGENE HD Transfection Reagent (Promega, WI, USA) into Opti-MEM 1. We added the diluted FuGENE dropwise to the DNA solution and incubated the mixture for 15 minutes at room temperature. We added the DNA-FuGENE complex directly to each dish and incubated the cells in a $\mathrm{CO}_{2}$ incubator at $37^{\circ} \mathrm{C}$ overnight. The overnight culture medium was replaced with fresh DMEM medium supplemented with $4 \%$ heat-inactivated fetal bovine serum, penicillin-streptomycin, and 1/500 volume of TiterBoost reagent (GeneCopoeia). Supernatants were collected $48 \mathrm{~h}$ after transfection, filtrated through $0.45 \mu \mathrm{m}$ polyethersulfone (PES) low-protein-binding filters (Whatman, NJ, USA), and concentrated 40 times by Lenti-X Concentrator (Clontech) according to the manufacturer's protocols.
The concentrated supernatant containing lentiviral particles was used directly to determine the titer and to transduce target cells in vitro. Lentiviral stocks were aliquoted and stored at $-80^{\circ} \mathrm{C}$. The titer of each batch of lentiviral vectors was assessed using the Lenti-X qRT-PCR titration kit (Clontech).

We plated $2 \times 10^{4}$ of the target P1 hBMSCs per well in a 24well plate $24 \mathrm{~h}$ prior to viral infection. For each well, $0.5 \mathrm{~mL}$ of virus suspension was diluted in growth medium with polybrene at a final concentration of $4 \mu \mathrm{g} / \mathrm{mL}$. We infected BMSCs by replacing the growth medium over the cells with the diluted viral supernatant [multiplicity of infection: 250 $(\mathrm{MOI}=250)$ ] and incubating the cells for $2 \mathrm{~h}$ at $4^{\circ} \mathrm{C}$, followed by transfer to a $37^{\circ} \mathrm{C}$ incubator with $5 \% \mathrm{CO}_{2}$ and incubation overnight. The viral supernatant medium was then removed and lentivirus- (LV-) transduced BMSCs were replated at a density of 80 cells $/ \mathrm{cm}^{2}$ (clonal density) or $2 \times 10^{3}$ cells $/ \mathrm{cm}^{2}$ onto a 6-well plate and used for further assays.

2.5. Adhesion Assays. Culture plates for adhesion assays were coated with $7 \mu \mathrm{g} / \mathrm{mL}$ collagen I for $1 \mathrm{~h}$ at $37^{\circ} \mathrm{C}$ and then blocked with $1 \%$ BSA in DMEM. LV-transduced BMSCs were replated at a density of $2 \times 10^{3}$ cells $/ \mathrm{cm}^{2}$ onto a 6 well plate precoated with collagen I incubated for $24 \mathrm{~h}$ at $37^{\circ} \mathrm{C}$. At 2 days after transduction, the nonadherent cells were removed by extensive, aggressive washing with $\mathrm{PBS}$. The remaining adherent cells were then trypsinized and counted in a hemocytometer. Nontreated cells were used as a control. To calculate relative cell attachment, the number of attached cells was normalized to the number of control attached cells. 


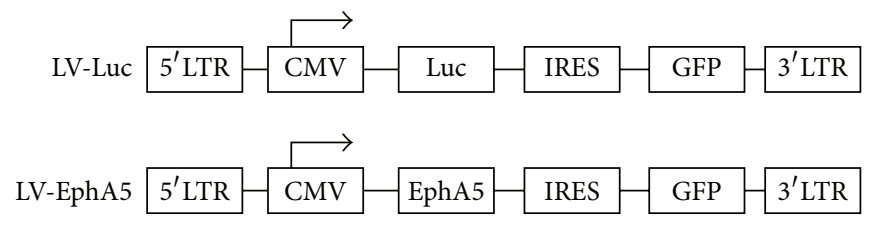

(a)

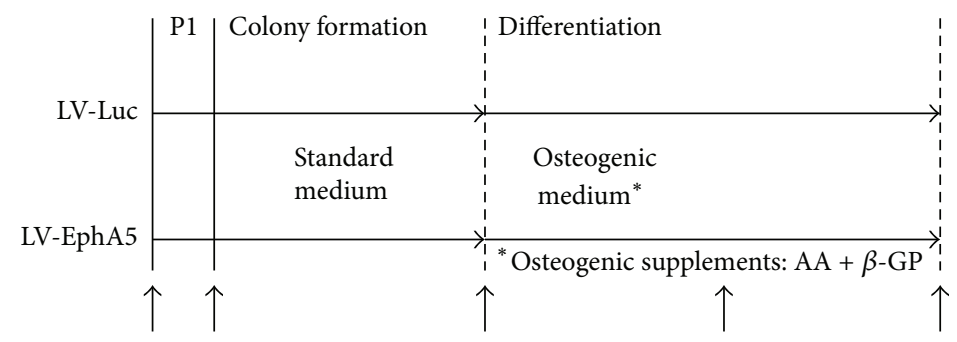

Start of Day 1 Day 2

Day 8

Day 15

Day 22

transduction Subculture Adhesion

ALP staining

von Kossa

assay

RT-PCR

staining

(b)
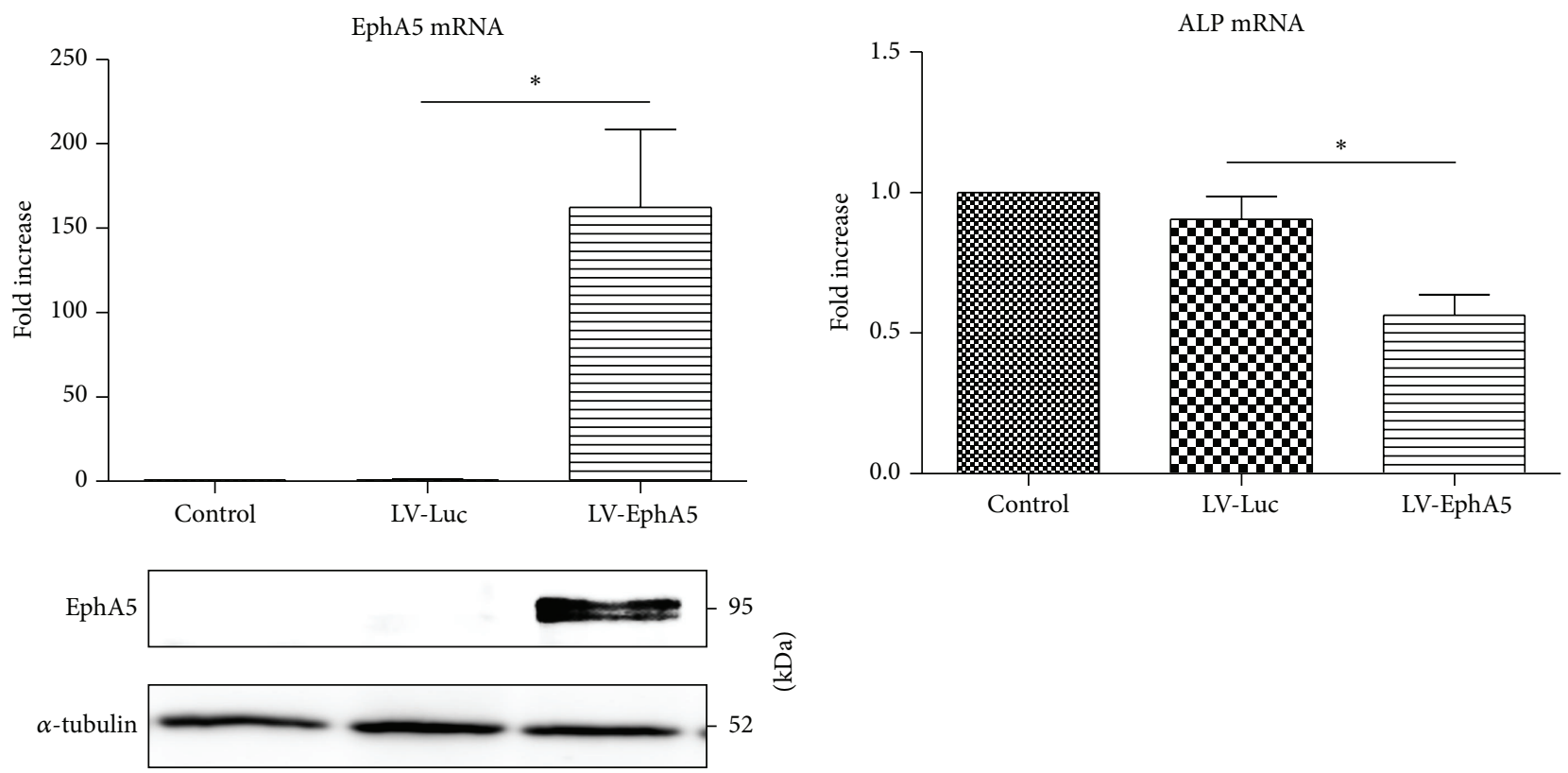

(c)

(d)

RUNX2 mRNA

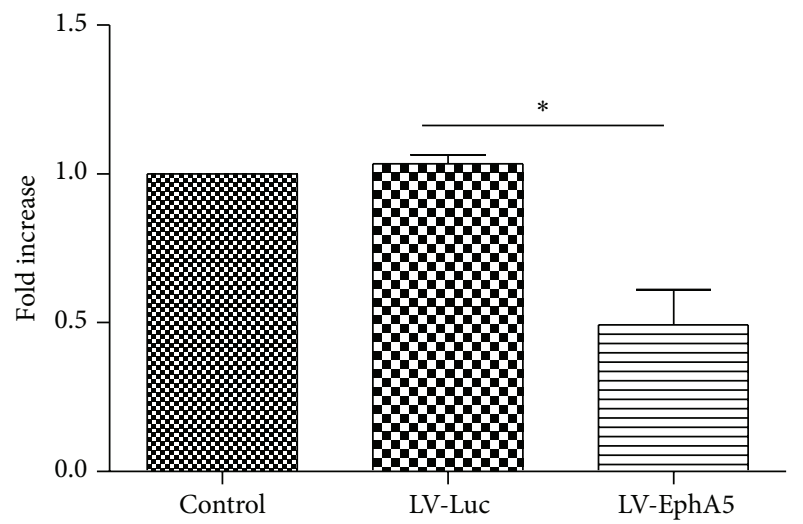

(e)

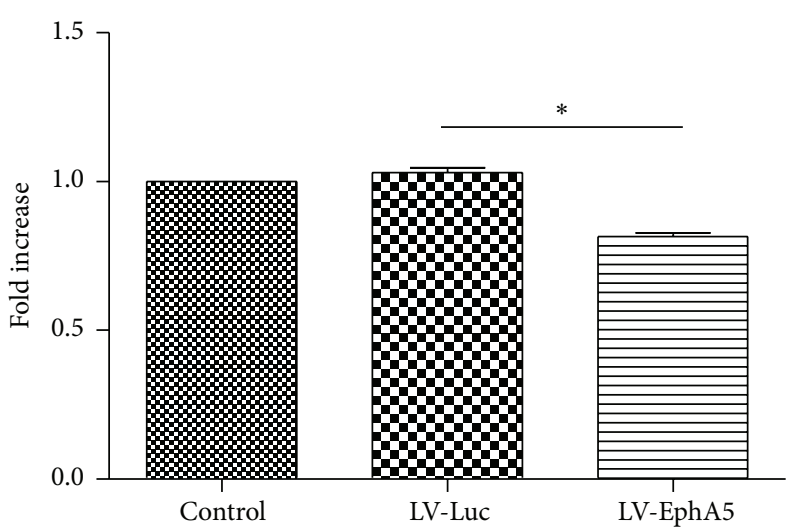

(f)

FIGURe 1: Continued. 


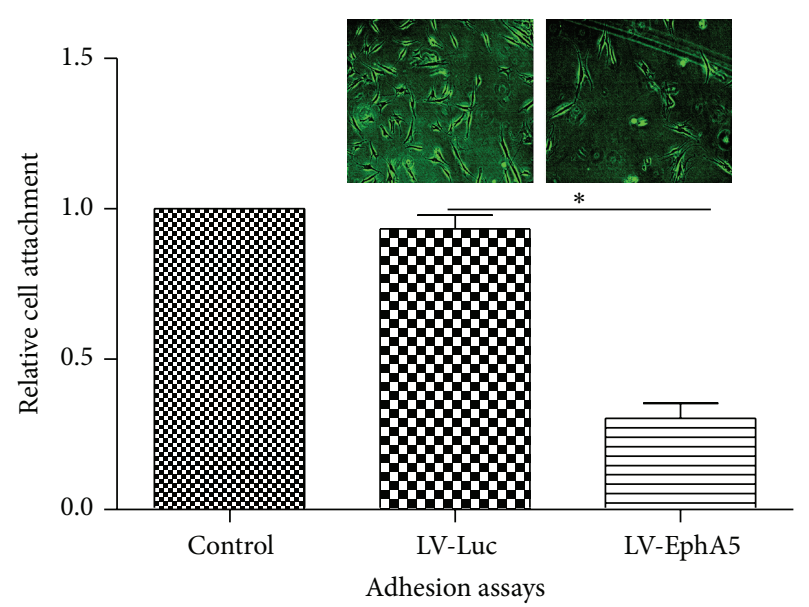

(g)
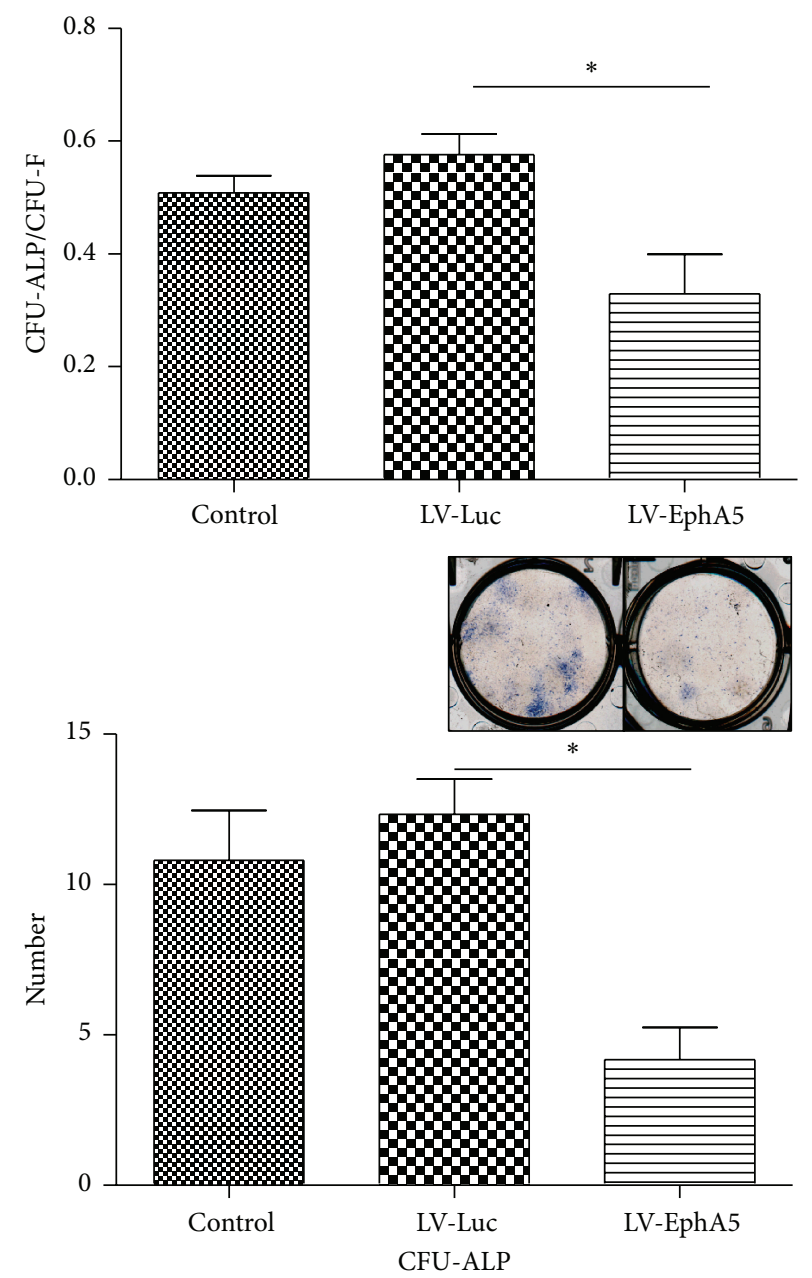

(i)

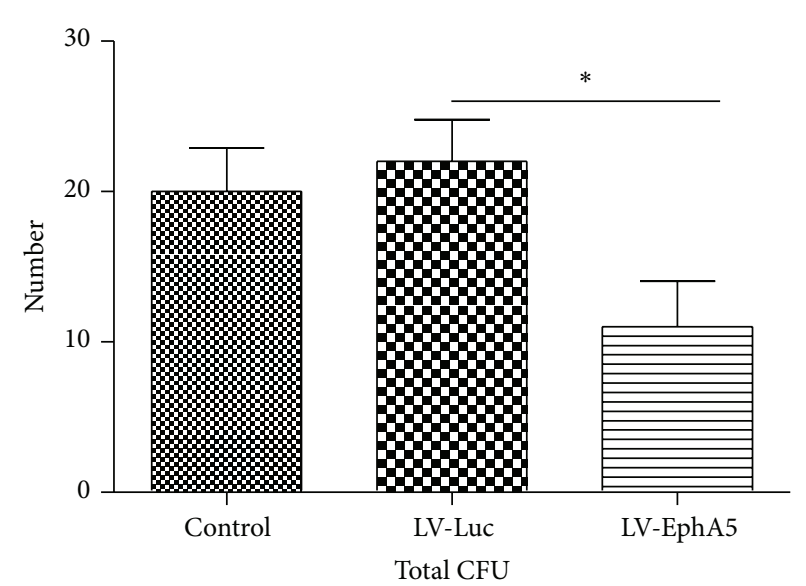

(h)
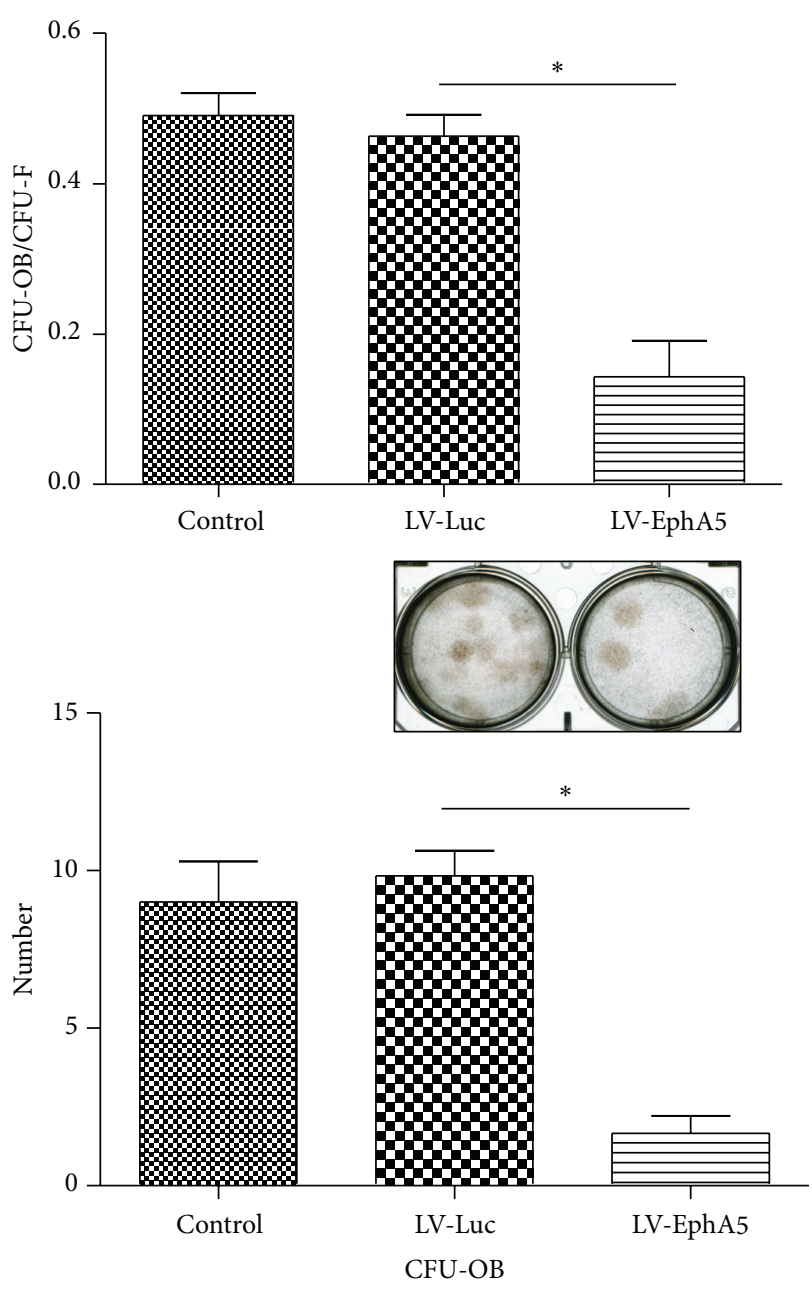

(j)

FIGURE 1: Forced expression of EphA5 inhibits osteoblast differentiation in hBMSCs. (a) Lentiviral constructs for transducing Luc and EphA5. (b) Schematic representation of the cell culture protocol. Adult hBMSCs were transduced with LV-Luc or LV-EphA5. ((c)-(f)) Quantitative analysis of mRNA expression of osteogenic markers at 7 days of osteogenic culture: (c) EphA5, (d) ALP, (e) Runx-2, and (f) ITGA5 ( $n=4$ ). The fold change of gene expression was normalized against the expression in cell cultures without LV transduction. ((c), lower) EphA5 protein levels were determined by western blot analysis. (g) Adhesion assays $(n=4)$. Images of cell attachment (upper). ((h)-(j)) CFU assays $(n=4)$. (h) Number of total colonies. (i) CFU-ALP positive rate (upper) and number of ALP-positive colonies (lower). Images of wells after ALP staining (middle). (j) CFU-OB positive rate (upper) and number of OB-positive colonies (lower). Images of wells after von Kossa staining (middle). 
2.6. CFU Assay. For clonal analysis, colony-forming unit (CFU) assays were performed. BMSCs were plated at 800 cells/well in 6-well culture plates and maintained in each medium for 7 days to form single cell-derived colonies, respectively. Then, the medium was changed to an osteogenic medium (CFU-ALP and CFU-OB).

2.7. CFU-ALP. Dishes were stained for ALP at 7 days of osteogenic induction. Dishes fixed with $10 \%$ neutral buffered formalin were washed with PBS and then incubated with a filtered mixture of naphthol AS-MX phosphate $(0.1 \mathrm{mg} / \mathrm{mL}$, Sigma-Aldrich Co.), N,N-dimethylformamide (0.5\%, Wako), $\mathrm{MgCl}_{2}(2 \mathrm{mM})$, and Fast Blue BB salt $(0.6 \mathrm{mg} / \mathrm{mL}$, SigmaAldrich) in $0.1 \mathrm{M}$ Tris- $\mathrm{Cl}(\mathrm{pH} 8.5)$ for $30 \mathrm{~min}$ at room temperature.

2.8. CFU-OB. Mineralized colonies were identified by von Kossa staining and designated as colony-forming unitosteoblasts (CFU-OB). At 14 days of osteogenic induction, cells were washed twice with Gey's balanced salt solution, fixed with $10 \%$ formalin, rinsed with $0.1 \mathrm{~mol} / \mathrm{L}$ cacodylic buffer, and covered with $1.0 \mathrm{~mL}$ of $5 \%$ silver nitrate (Wako). The cells were then exposed to UV light for $1 \mathrm{~h}$. Finally, the dishes were rinsed with distilled water and air-dried.

After positive colonies were counted in each assay, the dishes were stained with crystal violet to visualize all colonies present on the dishes, and the total number of colonies was determined. Colonies with a diameter $<2 \mathrm{~mm}$ and faintly stained colonies were ignored.

2.9. von Kossa Staining for Calcium Deposits. Cells were fixed with $10 \%$ formalin for $10 \mathrm{~min}$ at $4^{\circ} \mathrm{C}$ and washed with water three times, after which the cells were incubated with $3 \%$ silver nitrate for $60 \mathrm{~min}$ and exposed to light from a $40 \mathrm{~W}$ lamp. After rinsing with water, the cells were incubated with $5 \%$ sodium thiosulfate for $2 \mathrm{~min}$ followed by washing with water.

2.10. Western Blot Analysis. Proteins were extracted from hBMSCs. Total cellular protein was prepared by lysing cells in RIPA buffer at various time points. The protein concentration was determined using the BCA Protein Reagent Kit (Pierce, Rockford, IL). A primary antibody for EphA5 (AP7610d, ABGENT) and $\alpha$-tubulin (11H10) rabbit $\mathrm{mAb}$ (\#2125S, Cell Signaling Technology, Inc., Tokyo, Japan) were obtained. Protein $(15 \mu \mathrm{g})$ was separated by $10 \%$ SDS-PAGE and then transferred to a polyvinylidene difluoride (PVDF) membrane. After blocking with PVDF Blocking Reagent for Can Get Signal (TOYOBO Life Science, Tokyo, Japan), membranes were hybridized with the primary antibody overnight at $4^{\circ} \mathrm{C}$ and then hybridized with HRP-linked antirabbit immunoglobulin G secondary antibody (\#7074, Cell Signaling Technology, Inc., Tokyo, Japan) for $1 \mathrm{~h}$ at room temperature. We then added Lumigen TMA-6 (Lumigen Inc., Southfield, MI, USA) onto the membrane and let it stand for 2 minutes. The signals were detected using an enhanced chemiluminescence method on an ImageQuant LAS4000 Series system (GE Healthcare UK Ltd., England).
2.11. Microarray Analysis. The total RNA from subconfluent nontreated BMSCs and BMSCs treated with DEX for $6 \mathrm{~h}$ at $\mathrm{P} 5$ was isolated and then treated with DNasel for microarray analysis. Total RNA $(1 \mu \mathrm{g})$ was amplified and labeled with Cy3 or Cy5 using the Ambion Amino Allyl MessageAmp II aRNA Amplification Kit (Life Technologies, Cat. Number 1753) according to the manufacturer's instructions. An Agilent Whole Human Genome Microarray $4 \times 44 \mathrm{~K}$ (G4110F) was hybridized with $825 \mathrm{ng}$ of amplified RNA at $65^{\circ} \mathrm{C}$ for $16 \mathrm{~h}$ and washed using a Fluidics Station 450 system (Affymetrix, Inc., Santa Clara, CA, USA). The microarray slides were scanned using a GenePix 4000B scanner from Axon Instruments (Union City, CA, USA), and each microarray image was first analyzed using GenePix Pro 6.1 image analysis software (Molecular Devices, LLC, Sunnyvale, CA, USA) to determine the Cy3 and Cy5 fluorescence intensity and background noise for all spots on the array. The microarray data were normalized to the median value, and $\log _{2}$ ratios were calculated versus the values for the nontreated groups of the corresponding donor sample $(n=9)$. Genes that were up- or downregulated by more than threefold relative to the median value for all donor samples were further classified according to their protein types using the SOSUI program (http://bp.nuap.nagoya-u.ac.jp/sosui/).

2.12. Flow Cytometry Analysis. BMSCs cultured on a $100 \mathrm{~mm}$ culture dish with or without DEX treatment (100 nM, 14 days) were harvested by trypsinization. To identify ALPpositive cells, the collected cells were incubated for $30 \mathrm{~min}$ at $4^{\circ} \mathrm{C}$ with mouse monoclonal anti-human ALP antibody (R\&D systems, Inc., Minneapolis, MN, USA) and washed and incubated with FITC-conjugated secondary antibody (rat anti-mouse IgG1 monoclonal antibody; Becton, Dickinson and Company) for $30 \mathrm{~min}$ at $4^{\circ} \mathrm{C}$. Flow cytometric analyses were performed using a FACS Calibur system.

2.13. Ephrin-Fc and EphA5-Fc Treatment. Subconfluent monolayers of cells in 6-well plates were incubated with 0 , 0.4 , or $4 \mu \mathrm{g} / \mathrm{mL}$ Fc (6-001-A, R\&D Systems, Inc., MN, USA), ephrin-Fc (SMPK3, R\&D Systems, Inc.), or recombinant rat EphA5-Fc chimera (541-A5, R\&D Systems, Inc.) in DMEM containing $10 \%$ fetal bovine serum, $50 \mu \mathrm{g} / \mathrm{mL}$ ascorbic acid (Sigma-Aldrich Co.), and $10 \mathrm{mM} \beta$-glycerophosphate (Wako) for the indicated times. The mRNA expression level of ALP at day 7 was measured in P1 and P5 cells $(n=4)$.

2.14. 5-Azacytidine and VPA Treatment. Valproic acid (VPA, P4543, Sigma, St. Louis, MO, USA) was dissolved in $\mathrm{H}_{2} \mathrm{O}$ at a concentration of $1 \mathrm{M}$ and added to the culture medium at a final concentration of $1 \mathrm{mM}$. BMSCs were cultured in media supplemented with $10 \mu \mathrm{M} 5$-azacytidine (A2385, Sigma) or 5-aza-2' -deoxycytidine (A3656, Sigma) for 4 days or $1 \mathrm{mM}$ valproic acid for $24 \mathrm{~h}$.

2.15. Genomic DNA Extraction and Sodium Bisulfate DNA Modification. Genomic DNA was isolated from cells and tissues using the DNeasy Kit (Qiagen) and stored at $-20^{\circ} \mathrm{C}$ before use. Genomic DNA $(1 \mu \mathrm{g})$ from P1 cells or P5 cells 
was treated with sodium bisulfite according to the manufacturer's recommendations (EZ DNA Methylation-Gold Kit, Zymo Research, Orange, CA). Enzymatically methylated DNA (Universal Methylated Human DNA Standard, Zymo Research) was used as a positive control.

2.16. MSRE Digestion. Each reaction mixture for the OneStep qMethyl procedure was optimized for $20 \mathrm{ng}$ of input DNA according to the manufacturer's recommendations (OneStep qMethyl Kit, Zymo Research, Orange, CA). The designed primers were $5^{\prime}$-AGGAGGCTCGGAGAAGATGC$3^{\prime}$ (forward) and $5^{\prime}$-CATCTCCCTACCTTCGTTGCTG-3' (reverse), which amplify a DNA locus (region) that contains two methylation-sensitive restriction enzyme (MSRE) sites. The thermocycling conditions used were $37^{\circ} \mathrm{C}$ for $2 \mathrm{~h}$ during MSRE digestion; 1 cycle of $95^{\circ} \mathrm{C}$ for 10 minutes; 35 cycles of $95^{\circ} \mathrm{C}$ for 30 seconds, $63^{\circ} \mathrm{C}$ for 30 seconds, and $72^{\circ} \mathrm{C}$ for 30 seconds; and a final extension at $72^{\circ} \mathrm{C}$ for 7 minutes. The methylation level for amplified loci (regions) was determined using the following equation. Percent methylation $=100 \times$ $2^{-\Delta \mathrm{Ct}}$, where $\Delta \mathrm{Ct}$ is the average $\mathrm{Ct}$ value from the test reaction minus the average $\mathrm{Ct}$ value from the reference reaction.

2.17. Statistical Analysis. The values were expressed as the arithmetic mean \pm standard error of the mean (SEM) and analyzed using one-way analysis of variance (ANOVA). Then, Student's $t$-test was used for between-group comparisons. After the $p$ values were corrected using the Bonferroni correction, statistical significance was determined. Statistical significance is indicated by “*” in the graphs.

\section{Results}

3.1. Forced Expression of EphA5 Suppresses Osteogenic Differentiation in hBMSCs. To overexpress EphA5 in BMSCs and determine the role of EphA5 in osteogenic differentiation, hBMSCs were transduced with a lentiviral vector encoding EphA5 and GFP (Figures 1(a) and 1(b)). The LV-EphA5-transduced cells showed increased GFP expression and increased EphA5 mRNA levels at 7 days of osteogenic culture (Figure 1(c)). EphA5 overexpression in hBMSCs decreased ALP mRNA, Runx2 mRNA, and ITGA5 mRNA expression levels (Figures 1(d), 1(e), and 1(f)) and did not affect EphA2 and EphA4 mRNA expression levels (S1 Figure, in Supplementary Material available online at http://dx.doi.org/10.1155/2016/1301608). LV-EphA5transduced BMSCs demonstrated decreased adhesion to 6well plates compared with LV-Luc-transduced BMSCs or control untreated BMSCs at 1 day after seeding. There were no marked differences in the cell morphology between LVLuc- and LV-EphA5-transduced BMCSs (Figure 1(g)).

Consistent with this effect, LV-EphA5 transduction in hBMSCs decreased the osteogenic capacity of the hBMSCs as indicated by negative ALP staining and selectively inhibited their colony formation. BMSCs transduced with the lentiviral vector at passage 1 were plated at clonal density and cultured in growth medium for 7 days through the colony formation period. Each well was then incubated in osteogenic medium for an additional 7 or 14 days. Colonies were stained and ALP-positive and OB-positive colonies were counted. The total colony number and ratio of ALP- and OB-positive colonies in the LV-EphA5-treated wells were lower than those in the LV-Luc-treated wells (Figures $1(\mathrm{~h})-1(\mathrm{j})$ ). These results demonstrate that forced expression of EphA5 is sufficient to decrease not only the expression of osteoblast markers and osteogenic capacity of primary hBMSCs but also cell attachment on culture wells.

\subsection{EphA5 is Upregulated in Late Culture and Downregulated} during Osteogenic Induction with DEX. We analyzed the expression of all known members of the ephrin and Eph families in the hBMSC cultures after osteogenic induction with DEX and BMP-2 (Figure 2(a)). When DEX treatment was continued for $72 \mathrm{~h}$, the mRNA expression of ephrinB1, EphA2, EphA5, EphB1, EphB2, and EphB3 among the ephrin receptor tyrosine kinase subfamily was decreased, whereas that of ephrin-B2 and EphB6 was increased. In contrast, BMP-2 treatment increased the expression of ephrinA4, ephrin-A5, EphA2, EphA3, EphA4, and EphA5. The expression pattern of ephrins and Eph receptors during osteogenic induction using BMP-2 thus differed from that during osteogenic induction using DEX. A synergetic effect of DEX and BMP-2 was observed, as demonstrated by increased ALP mRNA expression. Among the ephrin and Eph families, the expression pattern of EphA5 was closely related to that of EphA2 when hBMSCs were treated with DEX and/or BMP. For example, the fall in EphA5 and EphA2 levels by DEX treatment was matched by rises in EphA3 and EphA4 levels in most samples.

We investigated the effect of continuous DEX treatment throughout the proliferation stage of BMSCs on differentiation capability by comparing DEX-treated cells with untreated cells. DEX treatment throughout the culture period led to dramatic changes in cell morphology (Figure 2(b)). Larger ALP-positive subpopulations were observed after continuous DEX treatment, which indicates that selection of osteogenic cell populations occurred (Figure 2(b)). Furthermore, we evaluated the effect of intercellular contact on the osteogenic capability of BMSCs under different induction protocols (Figure 2(c)). Augmentation of ALP mRNA expression with DEX induction was observed irrespective of cell density, whereas DEX-excluded osteogenic induction exerted a stronger effect at a high cell density than at a low cell density (Figure 2(d)), possibly because of the effect of osteogenic factors requiring cell-cell contact, such as those expressed by aligned osteoblasts, or osteogenic humoral factors released from BMSCs at high density. In contrast, EphA5 mRNA expression was minimally affected by the cell density when the cells were subjected to DEX-excluded osteogenic induction (Figure 2(e), S2 Figures A and B).

To investigate DEX-mediated osteogenesis, BMSCs at P5 were stimulated with $10^{-7} \mathrm{M}$ DEX for various durations. Although the decrease in EphA5 mRNA levels showed biphasic changes, DEX treatment inhibited EphA5 mRNA expression for up to 6 hours in most samples, followed by increased expression of ALP (Figure 2(f)). On the other hand, BMP-2 treatment showed the increase in EphA5 mRNA 


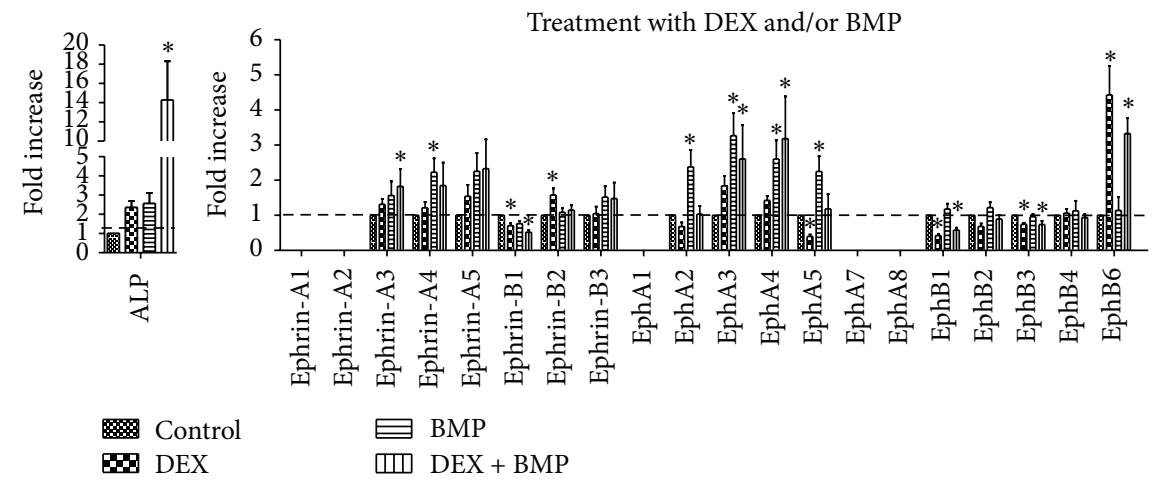

(a)
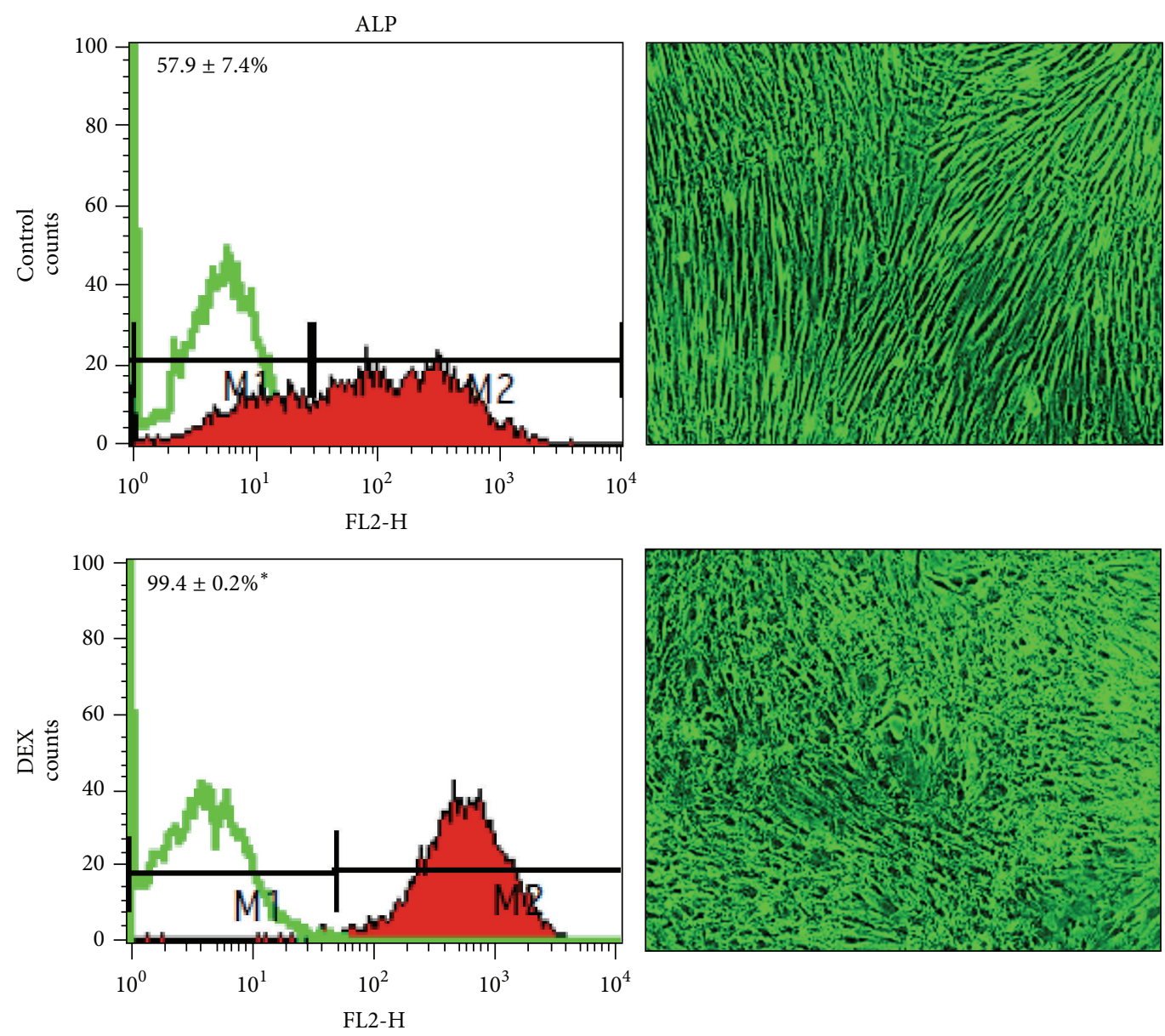

(b)

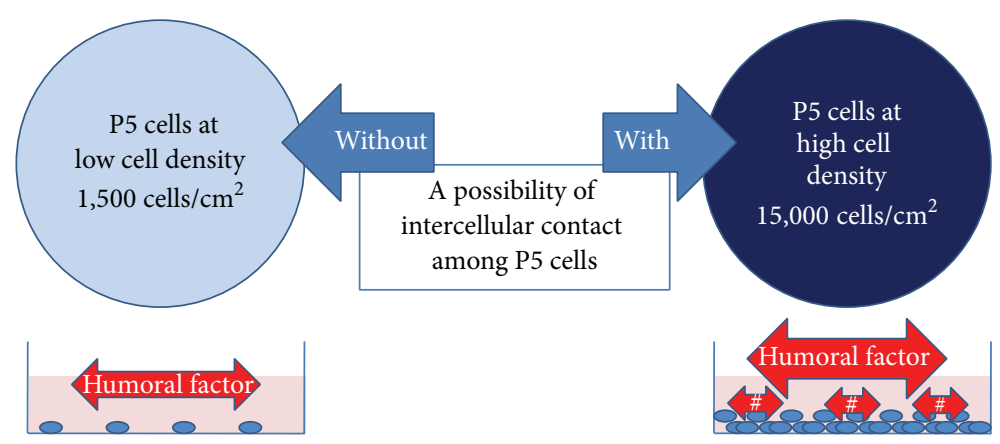

(c)

FIGURE 2: Continued. 

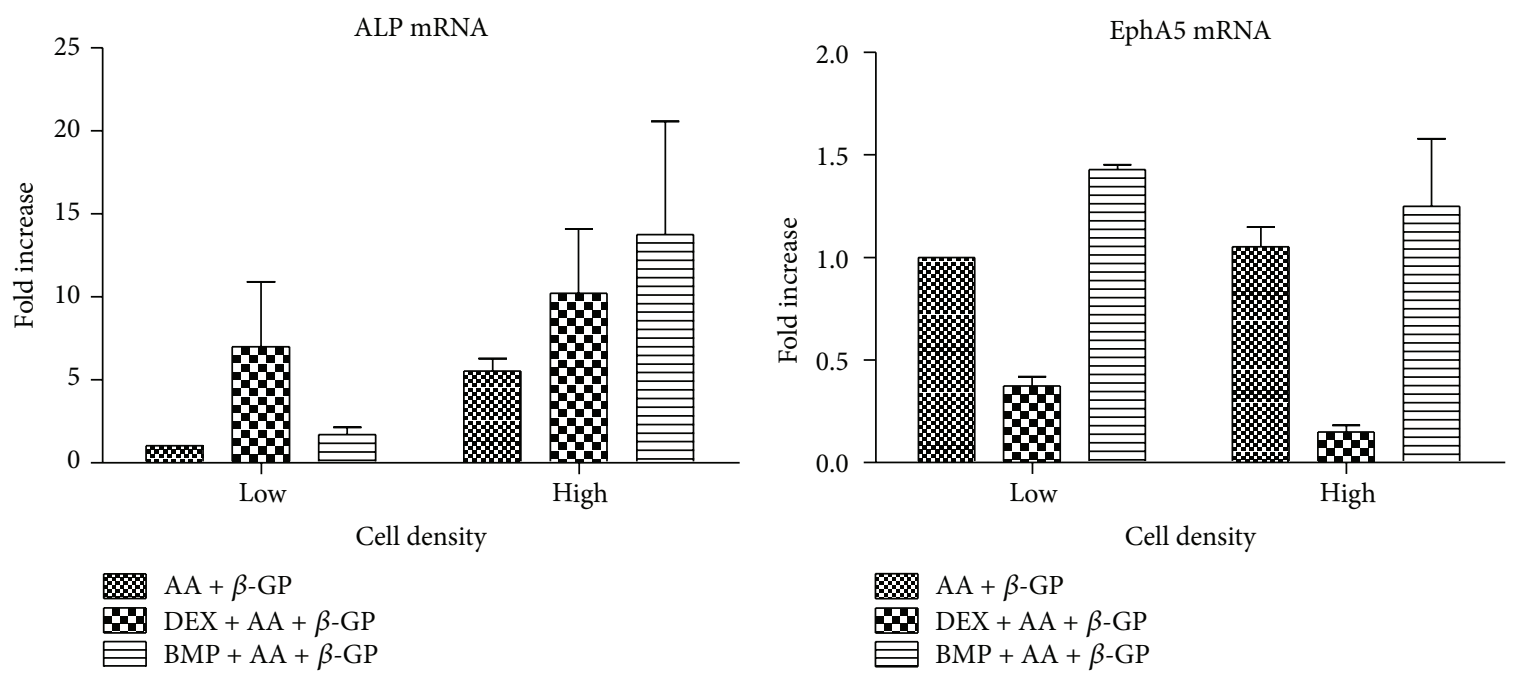

(d)

(e)

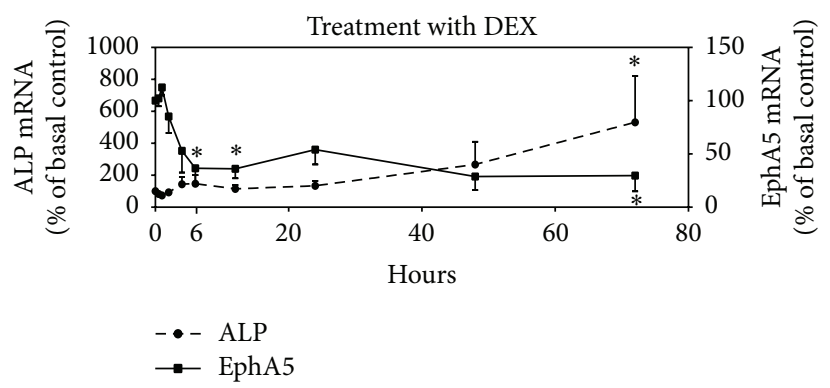

(f)

FIGURE 2: EphA5 is upregulated after repeated passaging and downregulated during osteogenic induction with DEX. (a) Expression of members of the ephrin and Eph receptor families in hBMSCs. P5 BMSCs were differentiated into osteogenic lineages using AA $+\beta$-GP + DEX or BMP-2, and quantitative PCR to determine the mRNA expression of ephrin and Eph receptor family members was performed at day 3 of osteogenic induction $(n=8)$. The fold change of gene expression was normalized against the expression level in the nontreated culture. DEX treatment suppressed and BMP treatment increased the mRNA expression of both EphA2 and EphA5, respectively. (b) Cell surface alkaline phosphatase (ALP) expression in hBMSCs at passage 5 was analyzed using flow cytometry $($ left, $n=4)$. Positive expression was defined as a level of fluorescence higher than $97 \%$ of the fluorescence obtained with the corresponding isotype-matched control antibody. Positive expression rates are displayed as the mean \pm SEM (green line, isotype control). DEX-treated cells showed a higher positive rate for ALP expression than untreated cells $\left({ }^{*} p<0.05\right)$. Cell bodies became smaller and showed morphological changes at day 14 of DEX treatment (right, magnification $\times 40)$. ((c)-(e)) Effect of cell density on ALP and EphA5 mRNA levels under different osteogenic induction protocols. (c) hBMSCs at P5 were seeded at low cell density, without intercellular contact, or at high cell density, that is, almost at confluency. \# shows intracellular contact between P1 and P5 cells. ((d), (e)) Quantitative analyses of (d) ALP and (e) EphA5 mRNA expression. The fold change of gene expression was normalized against the expression in cultures at low density with AA and $\beta$-GP treatment $(n=4)$ ). (f) Quantitative analyses of ALP and EphA5 mRNA expression in BMSCs at passage 5 when treated with DEX. The change in the expression of each gene expression was normalized against the expression in cell cultures prior to DEX addition $(n=9)$. EphA5 expression was transiently reduced after 2 hours of DEX induction and reached a minimum value after $6 \mathrm{~h}$ of induction. ALP expression was induced after $24 \mathrm{~h}$ of DEX induction, after which EphA5 expression gradually decreased again.

levels, leading to different results compared to DEX treatment (S2 Figure C).

To clarify the mechanism through which DEX promotes hBMSC osteogenesis, the differential gene expression of DEX-untreated BMSCs versus BMSCs treated with DEX for $6 \mathrm{~h}$ at P5 was analyzed by Affymetrix GeneChip technology for 9 independent BMSC preparations. The microarray analysis revealed that DEX treatment upregulated ITGA5 (Table 2) and its downstream target PIK3R1, in addition to FKBP5, the Src kinase family (SGEF, SHC4, SLA, and DIRAS3), FoxO1, and BMP-6. As expected, this treatment downregulated not only EphA5 but also downstream targets of EphA such as Rho/RAS-related genes (e.g., RASD1, ARHGAP, and RGNEF). Of note, DEX treatment altered the expression of various interleukins, tumor necrosis factors, and chemokine receptors (Tables 2 and 3). These dramatic changes caused by DEX induction may be a key to understanding the mechanism of osteogenic differentiation. ITGA5 upregulation induced by DEX has been reported to promote osteoblast differentiation of hBMSCs [16] and, in the present study, RT-PCR also revealed that osteogenic induction using DEX promoted ITGA5 expression at 7 days (S3 Figure). 
TABLE 2: Genes upregulated in hBMSCs by DEX treatment. Human genes upregulated by at least threefold in hBMSCs treated with DEX for $6 \mathrm{~h}$ at $\mathrm{P} 5$ compared with nontreated cells.

\begin{tabular}{|c|c|c|c|}
\hline Genes & & Gene bank & $\log _{2}$ ratio \\
\hline FKBP5 & FK506 binding protein 5 & NM_004117 & 3.932 \\
\hline CYP19A1 & Cytochrome P450, family 19, subfamily A, polypeptide 1, transcript variant 2 & NM_031226 & 3.880 \\
\hline HEYL & Hairy/enhancer-of-split related to YRPW motif-like & NM_014571 & 3.162 \\
\hline BMP6 & Bone morphogenetic protein 6 & NM_001718 & 3.006 \\
\hline DKK1 & Dickkopf homolog 1 (Xenopus laevis) & NM_012242 & 2.889 \\
\hline TNFAIP8L3 & Tumor necrosis factor, alpha-induced protein 8-like 3 & NM_207381 & 2.685 \\
\hline INHBB & Inhibin, beta B & NM_002193 & 2.653 \\
\hline MYPN & Myopalladin & NM_032578 & 2.594 \\
\hline CPM & Carboxypeptidase $\mathrm{M}$, transcript variant 1 & NM_001874 & 2.590 \\
\hline XIRP1 & Xin actin-binding repeat containing 1 & NM_194293 & 2.543 \\
\hline FOXO1 & Forkhead box O1 & NM_002015 & 2.413 \\
\hline CDH15 & Cadherin 15 , type $1, \mathrm{M}$-cadherin (myotubule) & NM_004933 & 2.377 \\
\hline GAL & Galanin prepropeptide & NM_015973 & 2.345 \\
\hline SNCAIP & Synuclein, alpha interacting protein & NM_005460 & 2.338 \\
\hline RNF128 & Ring finger protein 128 , transcript variant 1 & NM_194463 & 2.293 \\
\hline PRICKLE2 & Prickle homolog 2 (Drosophila) & NM_198859 & 2.289 \\
\hline ADRA1B & Adrenergic, alpha-1B-, receptor & NM_000679 & 2.267 \\
\hline PTGER2 & Prostaglandin E receptor 2 (subtype EP2), $53 \mathrm{kDa}$ & NM_000956 & 2.254 \\
\hline PPP1R14C & Protein phosphatase 1, regulatory (inhibitor) subunit 14C & NM_030949 & 2.234 \\
\hline WISP1 & WNT1 inducible signaling pathway protein 1 , transcript variant 2 & NM_080838 & 2.220 \\
\hline ANGPTL4 & Angiopoietin-like 4 , transcript variant 1 & NM_139314 & 2.201 \\
\hline DIRAS3 & DIRAS family, GTP-binding RAS-like 3 & NM_004675 & 2.173 \\
\hline ZNF469 & Zinc finger protein 469 & NM_001127464 & 2.145 \\
\hline CRYGS & Crystallin, gamma S & NM_017541 & 2.140 \\
\hline MT1M & Metallothionein 1M & NM_176870 & 2.121 \\
\hline SHC4 & SHC (Src homology 2 domain containing) family, member 4 & NM_203349 & 2.070 \\
\hline SGEF & Src homology 3 domain-containing guanine nucleotide exchange factor & NM_015595 & 2.046 \\
\hline TET3 & Tet oncogene family member 3 & NM_144993 & 2.019 \\
\hline PAG1 & Phosphoprotein associated with glycosphingolipid microdomains 1 & NM_018440 & 1.986 \\
\hline EEPD1 & Endonuclease/exonuclease/phosphatase family domain containing 1 & NM_030636 & 1.980 \\
\hline SLC20A1 & Solute carrier family 20 (phosphate transporter), member 1 & NM_005415 & 1.971 \\
\hline CMKLR1 & Chemokine-like receptor 1 , transcript variant 1 & NM_001142343 & 1.970 \\
\hline FABP5 & Fatty acid binding protein 5 (psoriasis-associated) & NM_001444 & 1.948 \\
\hline ABLIM3 & Actin binding LIM protein family, member 3 & NM_014945 & 1.944 \\
\hline SEC14L2 & SEC14-like 2 (S. cerevisiae), transcript variant 1 & NM_012429 & 1.942 \\
\hline CAMK2N1 & Calcium/calmodulin-dependent protein kinase II inhibitor 1 & NM_018584 & 1.906 \\
\hline HS3ST3B1 & Heparan sulfate (glucosamine) 3-O-sulfotransferase 3B1 & NM_006041 & 1.839 \\
\hline KBTBD11 & Kelch repeat and BTB (POZ) domain containing 11 & NM_014867 & 1.829 \\
\hline WNT5B & Wingless-type MMTV integration site family, member 5B, transcript variant 2 & NM_030775 & 1.817 \\
\hline SLA & Src-like adaptor, transcript variant 1 & NM_001045556 & 1.788 \\
\hline MT1G & Metallothionein $1 \mathrm{G}$ & NM_005950 & 1.781 \\
\hline MT1A & Metallothionein 1A & NM_005946 & 1.780 \\
\hline TOP1 & Topoisomerase (DNA) I & NM_003286 & 1.771 \\
\hline MTSS1 & Metastasis suppressor 1 & NM_014751 & 1.765 \\
\hline BAIAP2 & BAIl-associated protein 2, transcript variant 3 & NM_006340 & 1.750 \\
\hline IRAK3 & Interleukin-1 receptor-associated kinase 3 , transcript variant 1 & NM_007199 & 1.740 \\
\hline MT1B & Metallothionein 1B & NM_005947 & 1.734 \\
\hline FADS1 & Fatty acid desaturase 1 & NM_013402 & 1.725 \\
\hline ABTB2 & Ankyrin repeat and BTB (POZ) domain containing 2 & NM_145804 & 1.715 \\
\hline
\end{tabular}


TABLE 2: Continued.

\begin{tabular}{llc}
\hline Genes & & Gene bank \\
\hline JARID2 & Jumonji, AT rich interactive domain 2 & NM_004973 \\
ITGA5 & Integrin, alpha 5 (fibronectin receptor, alpha polypeptide) & 1.686 \\
MT1X & Metallothionein 1X & NM_002205 \\
GJB3 & Gap junction protein, beta 3, 31 kDa, transcript variant 1 & NM_005952 \\
MT1H & Metallothionein 1H & NM_024009 \\
HIVEP3 & Human immunodeficiency virus type I enhancer binding protein 3 & NM_005951 \\
TCF7 & Transcription factor 7 (T-cell specific, HMG-box), transcript variant 1 & NM_024503 \\
NR2F1 & Nuclear receptor subfamily 2, group F, member 1 & NM_003202 \\
\hline
\end{tabular}

A total of 28,780 human genes consistent with the quality criteria, genes upregulated threefold or higher are listed.

EphA5 and ITGA5 may therefore be involved in this DEXmediated osteogenic pathway.

\section{3. hBMSCs Treated with EphA5-Fc and Untreated hBMSCs} Express ALP mRNA at Similar Levels. In many cell types, Eph forward signaling and ephrin reverse signaling mediate opposite effects. It is therefore important to determine which signal contributes to the deterioration of the differentiation capability of hBMSCs. To clarify the opposite effects of Eph forward signaling and ephrin reverse signaling on the differentiation capability of hBMSCs, we first used various ephrin-Fc constructs to stimulate Eph forward signaling. Treatment with ephrin-A-Fc, which mainly activates various EphA forward signaling pathways, did not affect ALP mRNA levels, while treatment with ephrin-B-Fc significantly increased ALP mRNA expression (Figure 3(a)).

We performed q-PCR assays of cells cultured in the presence of a soluble form of the EphA5 extracellular domain fused to $\mathrm{Fc}$ (EphA5-Fc), based on the hypothesis that the EphA5-Fc soluble receptor, upon binding to ephrin ligands, would activate ephrin reverse signaling and inhibit Eph forward signaling by competing with the endogenous EphA5 receptor to bind to the ephrin ligand in hBMSCs. However, we found that exogenous addition of soluble EphA5-Fc did not affect ALP mRNA expression levels in either P1 cells or P5 cells (Figure 3(b)).

3.4. Silencing of EphA5 in Early-Passage hBMSCs Is Not Associated with Aberrant Hypermethylation of Its Promoter. EphA5 was prominently upregulated over the course of hBMSC proliferation. This mechanism may be associated with active suppression at lower passage numbers. To further elucidate the mechanism underlying the silencing of EphA5 in early-passage P1 cells, we analyzed the $5^{\prime}$ regulatory region of the EphA5 gene. In particular, we analyzed a 406 bp segment of a CpG island encompassing the TSS (transcription start site) $(-103$ to $+303 \mathrm{bp}$; TSS, +1$)$ that contains $38 \mathrm{CpG}$ dinucleotides; this segment spans the core promoter exon and part of intron 1. The methylation level for the EphA5 promoter, which contains two methylationsensitive restriction enzyme (MSRE) sites, was determined. The methylation level for the EphA5 promoter in hBMSCs at P1 or P5 was similar to that in human nonmethylated DNA as a negative control. EphA5 promoter was barely methylated in P1 and P5 cells, even under DEX treatment (Figure 4(a)).

Treatment of hBMSCs with the DNA methylation inhibitors 5-azacytidine and 5-aza- $2^{\prime}$-deoxycytidine did not alter EphA5 mRNA expression, indicating a lack of sensitivity of EphA5 expression to genomic DNA methylation status. However, treatment with the histone deacetylase 1 (HDAC1) inhibitor valproic acid (VPA) for 24 hours significantly increased EphA5 mRNA expression in P1 and P5 cells (Figure 4(b)). We then evaluated whether passagedependent changes in histone deacetylation affected EphA5 expression by treating BMSCs at each passage with VPA. VPA treatment at $1 \mathrm{mM}$ only slightly increased EphA expression in late-passage cells (Figure 4(c)), which suggests that histone deacetylation suppresses EphA5 expression in early-passage cultures and that chromatin remodeling through histone deacetylation is a potential mechanism for silencing of the EphA5 gene.

\section{Discussion}

Eph and Eph-related receptors have been implicated in developmental events, particularly in the nervous system [17-22]. The role of Eph receptors and ephrin ligands in cell adhesion and migration [23-25], formation of tissue compartment borders [26-28], and regulation of cell proliferation in various tumors [29-35] is also well documented; however, their potential role in bone biology is only now beginning to emerge. Among the ephrin and Eph family members expressed in hBMSCs, only EphA5 was upregulated in late-passage cultures [5]. In this study, we focused on the effects of EphA5 on BMSC osteogenic differentiation and provided data showing that EphA5 is important for regulating the osteogenic differentiation capability of hBMSCs. Gain-of-function studies showed that EphA5 diminishes the expression of osteoblast phenotypic markers. Downregulation of endogenous EphA5 by specific siRNAs or DEX treatment promoted osteoblast marker expression and osteogenic differentiation [5]. Therefore, considering that prolonged culture periods reduce the osteogenic differentiation potential of hBMSCs and EphA5 is gradually upregulated during long-term culture [5] (S2 Figure B), EphA5 could be involved in both the dormancy process and normal growth regulation of BMSCs and could be a potential 
TABLE 3: Genes downregulated in hBMSCs by DEX treatment. Human genes downregulated by at least threefold in hBMSCs treated with DEX for $6 \mathrm{~h}$ at P5 compared with nontreated cells.

\begin{tabular}{|c|c|c|c|}
\hline Genes & & Genebank & $\log _{2}$ ratio \\
\hline EGR2 & $\begin{array}{l}\text { Early growth response } 2 \text { (Krox-20 homolog, Drosophila), transcript } \\
\text { variant } 1\end{array}$ & NM_000399 & -4.446 \\
\hline CXCL1 & $\begin{array}{l}\text { Chemokine (C-X-C motif) ligand } 1 \text { (melanoma growth stimulating } \\
\text { activity, alpha) }\end{array}$ & NM_001511 & -4.060 \\
\hline EGR1 & Early growth response 1 & NM_001964 & -3.989 \\
\hline CXCL2 & Chemokine (C-X-C motif) ligand 2 & NM_002089 & -3.925 \\
\hline ATF3 & Activating transcription factor 3 , transcript variant 4 & NM_001040619 & -3.847 \\
\hline EGR3 & Early growth response 3 & NM_004430 & -3.382 \\
\hline NR4A1 & Nuclear receptor subfamily 4 , group A, member 1 , transcript variant 1 & NM_002135 & -3.312 \\
\hline IER3 & Immediate early response 3 & NM_003897 & -3.294 \\
\hline SERTAD4 & SERTA domain containing 4 & NM_019605 & -3.142 \\
\hline FOS & v-fos FBJ murine osteosarcoma viral oncogene homolog & NM_005252 & -3.050 \\
\hline FOSB & $\begin{array}{l}\text { FBJ murine osteosarcoma viral oncogene homolog } B \text {, transcript } \\
\text { variant } 1\end{array}$ & NM_006732 & -3.042 \\
\hline CXCL3 & Chemokine (C-X-C motif) ligand 3 & NM_002090 & -2.950 \\
\hline $\mathrm{ZC} 3 \mathrm{H} 12 \mathrm{~A}$ & Zinc finger CCCH-type containing 12A & NM_025079 & -2.949 \\
\hline IL-8 & Interleukin-8 & NM_000584 & -2.917 \\
\hline GDF15 & Growth differentiation factor 15 & NM_004864 & -2.887 \\
\hline IL-6 & Interleukin-6 (interferon, beta 2) & NM_000600 & -2.886 \\
\hline MAP3K8 & Mitogen-activated protein kinase kinase kinase 8 & NM_005204 & -2.837 \\
\hline BTG2 & BTG family, member 2 & NM_006763 & -2.669 \\
\hline SEMA6D & $\begin{array}{l}\text { Sema domain, transmembrane domain (TM), and cytoplasmic } \\
\text { domain, (semaphorin) 6D, transcript variant } 6\end{array}$ & NM_024966 & -2.659 \\
\hline PTGS2 & $\begin{array}{l}\text { Prostaglandin-endoperoxide synthase } 2 \text { (prostaglandin G/H synthase } \\
\text { and cyclooxygenase) }\end{array}$ & NM_000963 & -2.586 \\
\hline HES1 & Hairy and enhancer of split 1, (Drosophila) & NM_005524 & -2.520 \\
\hline HAS3 & Hyaluronan synthase 3 , transcript variant 2 & NM_138612 & -2.502 \\
\hline NCOA7 & Nuclear receptor coactivator 7 , transcript variant 1 & NM_181782 & -2.390 \\
\hline EYA1 & Eyes absent homolog 1 (Drosophila), transcript variant 3 & NM_000503 & -2.376 \\
\hline JUNB & Jun B proto-oncogene & NM_002229 & -2.356 \\
\hline C10orf10 & Chromosome 10 open reading frame 10 (C10orf10) & NM_007021 & -2.347 \\
\hline PIM1 & Pim-1 oncogene & NM_002648 & -2.316 \\
\hline ST8SIA1 & ST8 alpha-N-acetyl-neuraminidase alpha-2,8-sialyltransferase 1 & NM_003034 & -2.256 \\
\hline C5orf41 & Chromosome 5 open reading frame 41 (C5orf41) & NM_153607 & -2.251 \\
\hline KLHL24 & Kelch-like 24 (Drosophila) & NM_017644 & -2.248 \\
\hline JUN & Jun oncogene & NM_002228 & -2.247 \\
\hline BCL2L11 & BCL2-like 11 (apoptosis facilitator), transcript variant 1 & NM_138621 & -2.227 \\
\hline EBF3 & Early B-cell factor 3 & NM_001005463 & -2.195 \\
\hline $\mathrm{NF} \kappa \mathrm{BIZ}$ & $\begin{array}{l}\text { Nuclear factor of kappa light polypeptide gene enhancer in B-cells } \\
\text { inhibitor, zeta, transcript variant } 1\end{array}$ & NM_031419 & -2.188 \\
\hline AMOTL2 & Angiomotin like 2 & NM_016201 & -2.160 \\
\hline TOX & Thymocyte selection-associated high mobility group box & NM_014729 & -2.149 \\
\hline NUAK2 & NUAK family, SNF1-like kinase, 2 & NM_030952 & -2.112 \\
\hline SASH1 & SAM and SH3 domain containing 1 & NM_015278 & -2.112 \\
\hline SLC40A1 & Solute carrier family 40 (iron-regulated transporter), member 1 & NM_014585 & -2.102 \\
\hline CCL2 & Chemokine (C-C motif) ligand 2 & NM_002982 & -2.089 \\
\hline ID4 & $\begin{array}{l}\text { Inhibitor of DNA binding } 4 \text {, dominant negative helix-loop-helix } \\
\text { protein }\end{array}$ & NM_001546 & -2.034 \\
\hline
\end{tabular}


TABLE 3: Continued.

\begin{tabular}{|c|c|c|c|}
\hline Genes & & Genebank & $\log _{2}$ ratio \\
\hline FAM110B & Family with sequence similarity 110 , member $B$ & NM_147189 & -2.030 \\
\hline AXUD1 & AXIN1 upregulated 1 & NM_033027 & -2.014 \\
\hline BCL3 & B-cell CLL/lymphoma 3 & NM_005178 & -2.011 \\
\hline ARL4C & ADP-ribosylation factor-like $4 \mathrm{C}$ & NM_005737 & -2.011 \\
\hline IER2 & Immediate early response 2 & NM_004907 & -2.009 \\
\hline RASD1 & RAS, dexamethasone-induced 1 & NM_016084 & -2.007 \\
\hline OSR2 & Odd-skipped related 2 (Drosophila), transcript variant 2 & NM_053001 & -1.985 \\
\hline GAB1 & GRB2-associated binding protein 1 , transcript variant 1 & NM_207123 & -1.977 \\
\hline TNFAIP3 & Tumor necrosis factor, alpha-induced protein 3 & NM_006290 & -1.954 \\
\hline PDK4 & Pyruvate dehydrogenase kinase, isozyme 4 & NM_002612 & -1.930 \\
\hline $\mathrm{BMP} 4$ & Bone morphogenetic protein 4 , transcript variant 1 & NM_001202 & -1.867 \\
\hline BDKRB1 & Bradykinin receptor $\mathrm{B} 1$ & NM_000710 & -1.849 \\
\hline IRF1 & Interferon regulatory factor 1 & NM_002198 & -1.840 \\
\hline N4BP2L1 & NEDD4 binding protein 2-like 1, transcript variant 1 & NM_052818 & -1.814 \\
\hline ARHGAP20 & Rho GTPase activating protein 20 & NM_020809 & -1.802 \\
\hline $\mathrm{NF} \kappa \mathrm{BIA}$ & $\begin{array}{l}\text { Nuclear factor of kappa light polypeptide gene enhancer in B-cells } \\
\text { inhibitor, alpha }\end{array}$ & NM_020529 & -1.801 \\
\hline CXCR7 & Chemokine (C-X-C motif) receptor 7 & NM_020311 & -1.789 \\
\hline RFTN2 & Raftlin family member 2 & NM_144629 & -1.774 \\
\hline PRICKLE1 & Prickle homolog 1 (Drosophila) & NM_153026 & -1.768 \\
\hline TIAM2 & T-cell lymphoma invasion and metastasis 2 , transcript variant 1 & NM_012454 & -1.753 \\
\hline BIRC3 & Baculoviral IAP repeat-containing 3, transcript variant 1 & NM_001165 & -1.751 \\
\hline C5orf4 & Chromosome 5 open reading frame 4 , transcript variant 2 & NM_032385 & -1.731 \\
\hline GATA6 & GATA binding protein 6 & NM_005257 & -1.729 \\
\hline CLDN23 & Claudin 23 & NM_194284 & -1.719 \\
\hline TNFRSF11B & Tumor necrosis factor receptor superfamily, member $11 b$ & NM_002546 & -1.700 \\
\hline C2orf67 & $\begin{array}{l}\text { Homo sapiens chromosome } 2 \text { open reading frame } 67 \text { (C2orf67), } \\
\text { mRNA [NM_152519] }\end{array}$ & NM_152519 & -1.693 \\
\hline TRIB3 & Tribbles homolog 3 (Drosophila) & NM_021158 & -1.693 \\
\hline EBF1 & Early B-cell factor 1 & NM_024007 & -1.684 \\
\hline PRAGMIN & Homolog of rat pragma of Rnd2 & NM_001080826 & -1.683 \\
\hline MAFB & $\begin{array}{l}\text { v-maf musculoaponeurotic fibrosarcoma oncogene homolog B } \\
\text { (avian) }\end{array}$ & NM_005461 & -1.680 \\
\hline ZFP36 & Zinc finger protein 36, C3H type, homolog (mouse) & NM_003407 & -1.673 \\
\hline IL-7 & Interleukin-7 & NM_000880 & -1.642 \\
\hline RUNX1T1 & $\begin{array}{l}\text { Runt-related transcription factor 1; translocated to, } 1 \text { (cyclin } \\
\text { D-related), transcript variant } 1\end{array}$ & NM_004349 & -1.628 \\
\hline HK2 & Hexokinase 2 & NM_000189 & -1.623 \\
\hline EPHA5 & EPH receptor A5, transcript variant 1 & NM_004439 & -1.186 \\
\hline
\end{tabular}

A total of 28,780 human genes consistent with the quality criteria, genes downregulated twofold or higher are listed.

candidate marker for replicative senescence. Previous reports suggested that EphA5 is involved in regulation of tumor dormancy $[36,37]$. Furthermore, several studies previously indicated that cell senescence-related genes are localized on human chromosome 4 , as introduction of normal human chromosome 4 into three immortal cell lines resulted in a loss of proliferation and reversal of the immortal phenotype $[4,38]$. In contrast to EphA2, which resides on chromosome 1; EphA3, EphB1, EphB2, and EphB3 on chromosome 3; EphA4 on chromosome 2; and EphB4 and EphB6 on chromosome 7, EphA5 is located on chromosome 4q13, which might further support its involvement in senescence.

In many cell types, Eph forward signaling and ephrin reverse signaling mediate opposite effects [39-41]. Emerging evidence suggests that cells coexpressing Eph receptors and ephrins exist in many tissues and the coexpression of EphAs and ephrin-A results in trans- (between adjacent cells) or cis- (in the same cell) interactions [42, 43]. Coclustering 


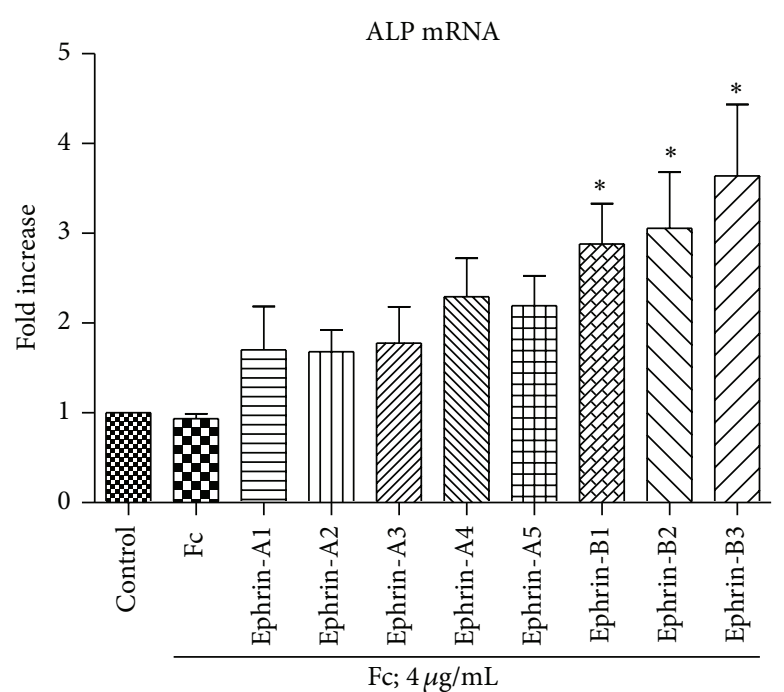

(a)
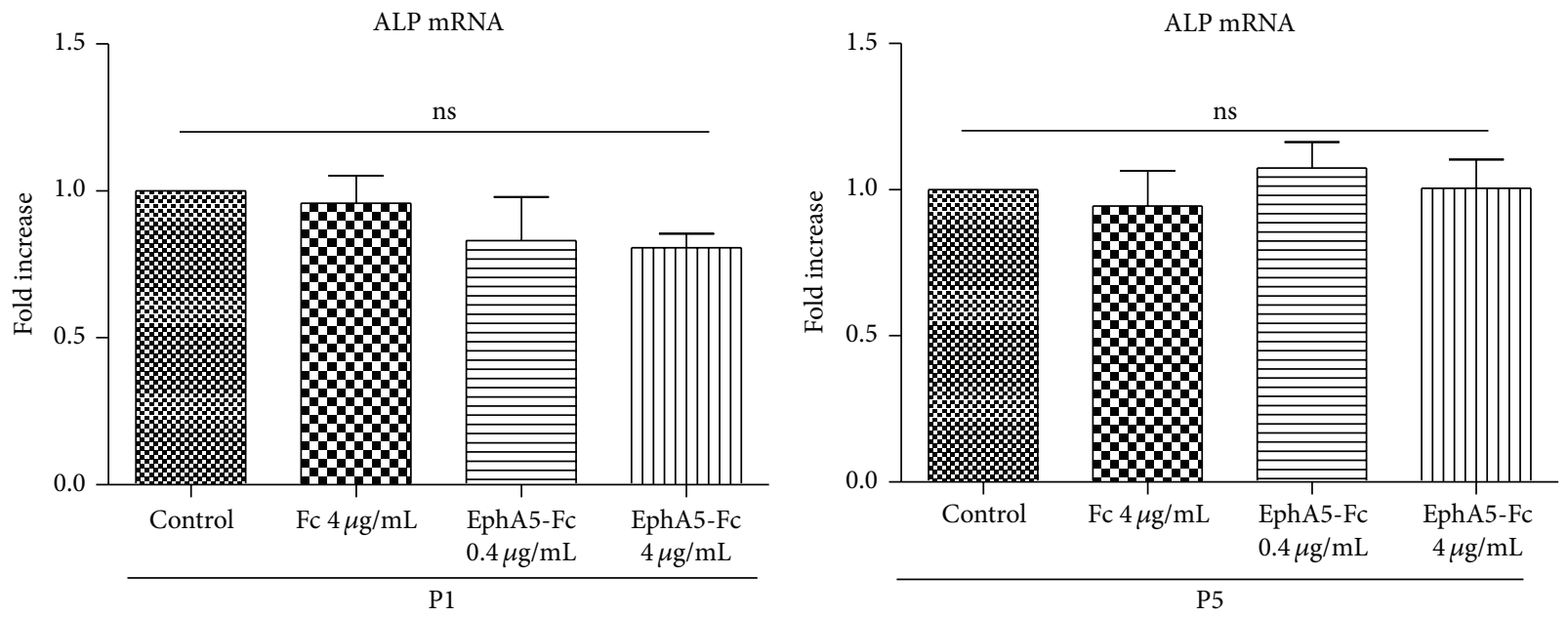

(b)

FIGURE 3: hBMSCs treated with EphA5-Fc express ALP mRNA at levels similar to those of nontreated hBMSCs. (a) hBMSCs at P5 were left untreated (control) or treated for 7 days with $4 \mu \mathrm{g} / \mathrm{mL}$ Fc or ephrin-Fc. Quantitative analysis of ALP mRNA expression $(n=4)$. The fold change of gene expression was normalized against the expression in cell cultures without Fc treatment. (b) hBMSCs at P1 (left) or P5 (right) were left untreated (control) or treated for 7 days with 0 or $4 \mu \mathrm{g} / \mathrm{mL} \mathrm{Fc}$ and EphA5-Fc. Quantitative analysis of ALP mRNA expression $(n=4)$. The fold change of gene expression was normalized against the expression in cell cultures without Fc treatment. Images of wells after ALP staining (upper).

occurs also between EphA and EphB receptors, resulting in activation of both receptor types that does not require the presence of both ligands, with outcomes depending on the relative receptor expression [44]. We previously found that various endogenous EphA and EphB receptors are expressed in hBMSC like tumor cells [5]. We now propose that coexpression of Eph receptors and ephrins regulates the osteogenic differentiation of hBMSCs. At early passages of hBMSC primary culture, EphA5 is expressed at low levels, independent of methylation. Under normal conditions, EphA5 and ephrin-As/ephrin-Bs are properly expressed and engaged with each other. The signaling triggered by EphA activation counteracts growth factor signaling by promoting activation of Ras/ERK and PI3K/Akt [45], which contributes to the maintenance of cell homeostasis. Repeated passaging results in selective upregulation of EphA5 but not ephrins [5] thereby leading to an excess of nonligated EphA5.

In the present study, although Eph forward signaling stimulated by ephrin-B-Fc promoted the expression of ALP mRNA in BMSCs as previously reported $[6,46,47]$ (Figure 3(a)), treatment with ephrin-A-Fc did not significantly affect osteogenic differentiation in vitro. In particular, exogenous addition of EphA5-Fc, which could activate ephrin reverse signaling or inhibit EphA5 forward signaling by competitive bindings, did not affect the ALP expression level. Moreover, although the expression of EphA5 at low cell density, where there is no possibility of intercellular contact among BMSCs, is nearly identical to that observed 


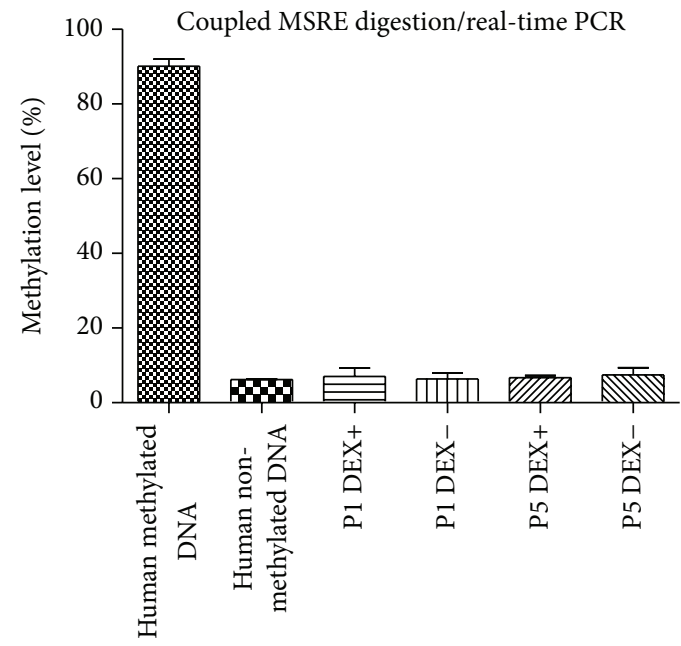

(a)
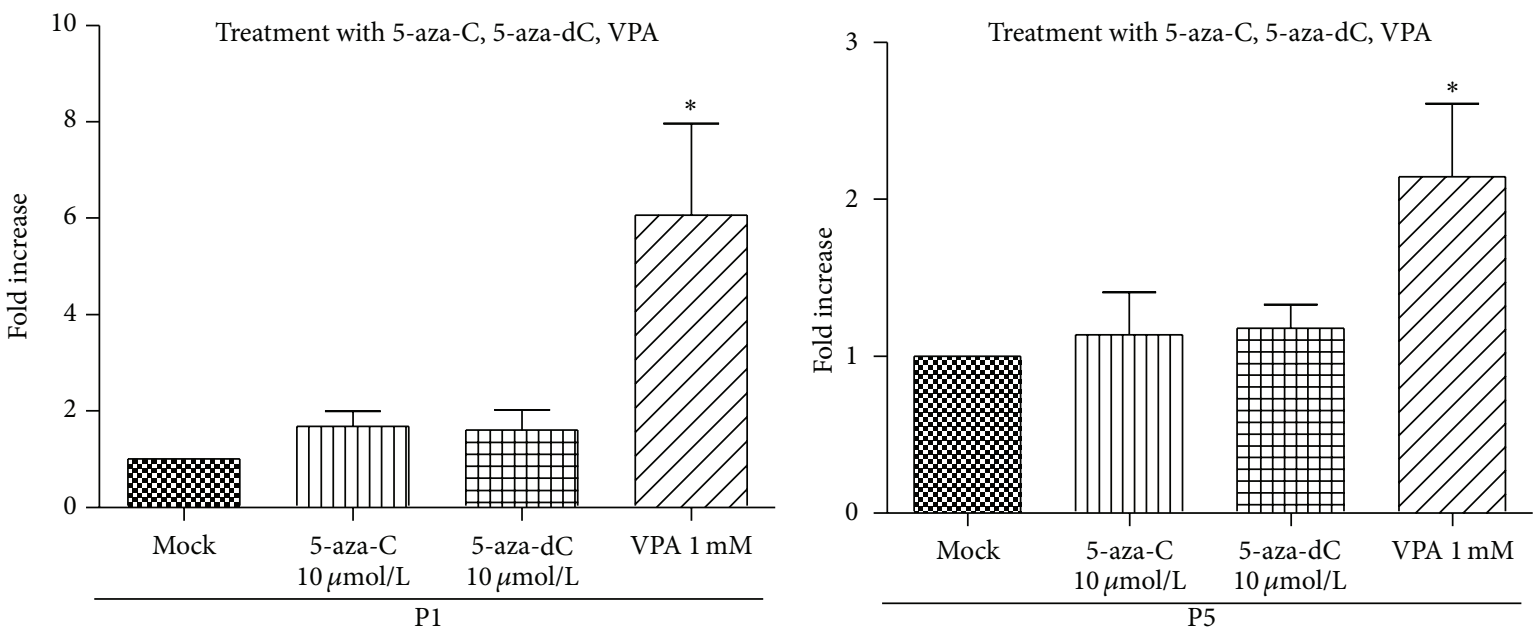

(b)

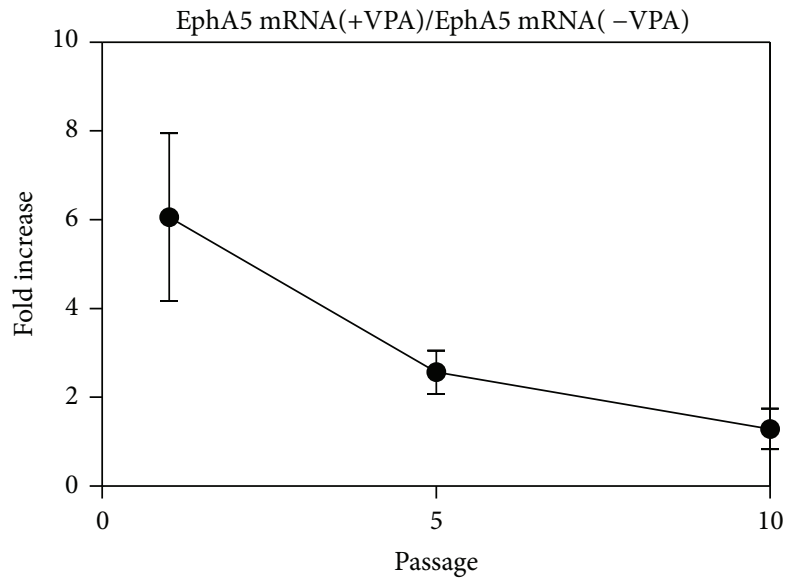

(c)

Figure 4: Silencing of EphA5 in early-passage hBMSCs is not associated with aberrant hypermethylation of the EphA5 promoter. (a) The methylation level for the EphA5 promoter that contains two Methylation-Sensitive Restriction Enzymes (MSRE) sites was determined $(n=4)$. The methylation level for the EphA5 promoter in hBMSCs at P1 and P5 was much lower than that in human methylated DNA used as a positive control (PC) and similar to that in human nonmethylated DNA used as a negative control (NC). (b) EphA5 mRNA expression analysis by quantitative RT-PCR in hBMSCs treated with 5-azacytidine (5-aza-C) or 5-aza-2' -deoxycytidine (5-aza-dC) for 4 days, or valproic acid (VPA) for 24 hours $(n=7)$. The fold change of gene expression was normalized to the expression in mock-treated cell cultures. (c) The fold change of in the EphA5 mRNA level caused by VPA treatment at the indicated culture passage numbers was measured $(n=5)$. 


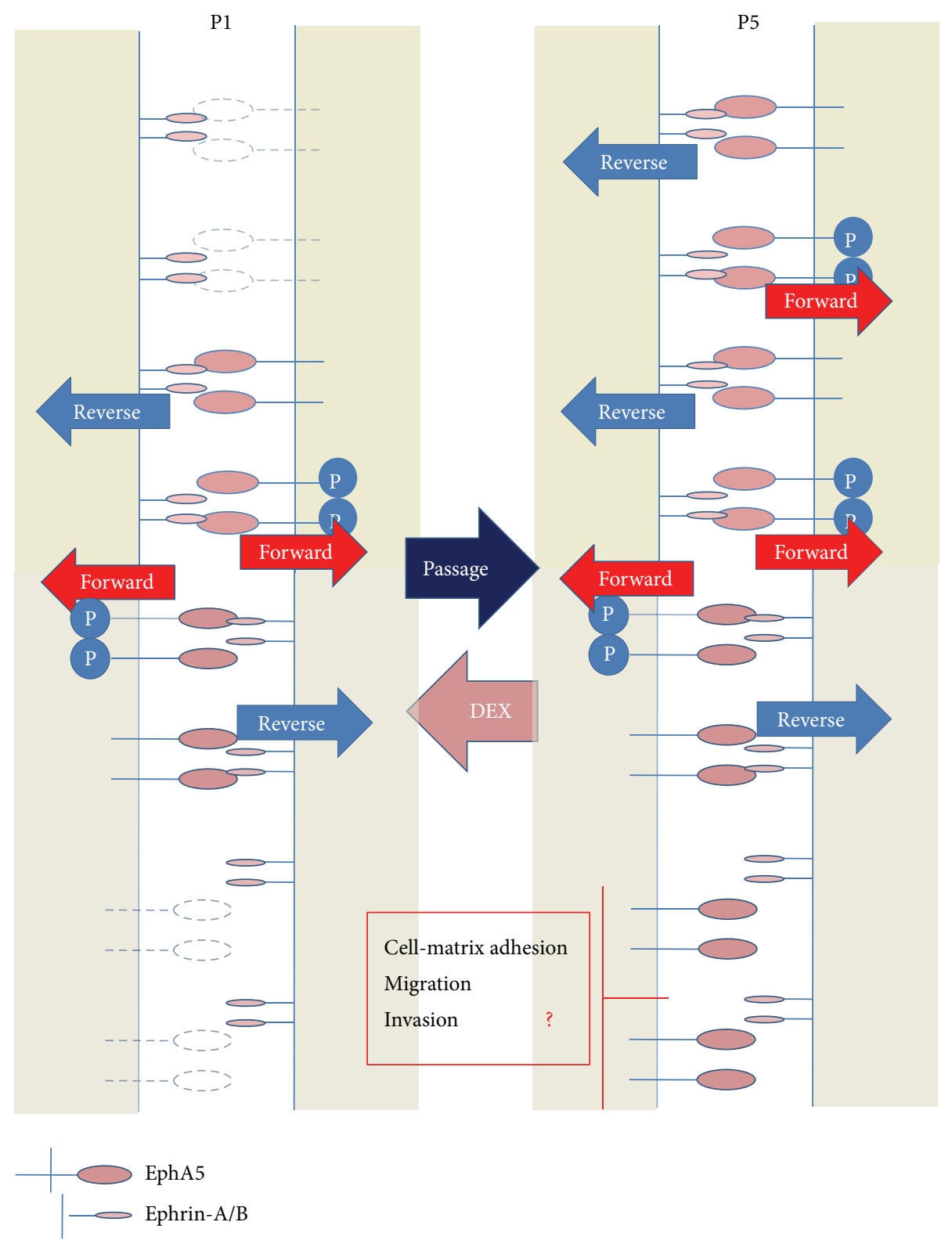

FIGURE 5: Proposed mechanisms by which EphA5 inhibits hBMSC osteogenesis. Coexpression of EphA5 and ephrins regulates hBMSC osteogenesis. Repeating passaging upregulates EphA5 but not ephrins, which results in an excess of nonligated EphA5. An imbalance between receptor and ligand expression may compromise other Eph ligand-dependent differentiation processes and promote ligand-independent suppression in hBMSCs.

at high cell density with cell-cell contact, the ALP mRNA level is lower at low cell density. Cell-cell contact such as osteoclast-osteoblast [6], osteoblast-osteoblast [7, 8], and BMSCs-BMSCs is generally supposed to be essential for the osteogenic differentiation. In the case that there is no cell-cell contact, the essential signaling for osteogenic differentiation may not be transmitted, leading to the fall in ALP levels. It is becoming increasingly clear that at least some Eph kinases can function without ligand engagement [48]. The increased expression of EphA5 could competitively prevent various ephrins from binding to other Eph receptors and thus inhibit osteogenic signal transduction pathways such as EphB forward signaling. Besides this mechanism, there is a possibility that a large excess of nonligated EphA5 during long-term culture, under physiologically abnormal conditions, may thus have some negligible effect on maintaining the undifferentiated state of BMSCs, independently of ligand binding (Figure 5(a)). Another possibility is that the canonical EphA5 forward signaling stimulated by ephrins or the ephrin reverse signaling stimulated by EphA5 itself does not transmit osteogenic signals. Rather, EphA5 may function to attenuate the signaling of coclustered catalytically incompetent receptors such as EphA10 and EphB6, which may mediate kinase-independent forward signals similarly to 
kinase-inactive variant forms of other Eph receptors [49-51]. The present results are difficult to interpret because of the complexity and lack of specificity of ephrin/Eph binding; for example, each ephrin can bind to more than one Eph receptor and vice versa, even between classes A and B. Moreover, the ephrin/Eph signals are transmitted bidirectionally. In general, Fc-clustered ligands are capable of activating the receptor in vitro. Although many authors use the ephrin$\mathrm{Fc}$ as the ligands which can activate Eph forward signals $[6,23,47,48,52]$, it also remains unclear whether the ephrinFc actually induced receptor activation; these ligands often act as inhibitors or blocking reagents rather than activators if not added after cross-linking. The downstream signaling of EphA5 is not supposed to be only one signaling but to be multiple and complicated. EphA5 may mediate the belowmentioned various different pathways and may lead to affect both the downstream signaling which promotes ALP expression and that which suppresses simultaneously, although the overexpression of EphA5 suppressed ALP expression as a result. Alternative EphA or EphB signaling involved in osteogenic induction, and not just EphA5 signaling alone, may participate in this process. Given the variability of Eph expression in hBMSCs, the present results alone could not fully represent the specific mechanism of EphA5 signaling. More global approach is needed to define the exact role of EphA5 beyond this limitation.

Eph receptors are also known to signal through various different pathways and molecules, including small GTPases of the Rho and Ras family, focal adhesion kinase (FAK), the Jak/Stat pathway, and the PI3K pathway. In the present study, DEX treatment downregulated not only EphA5 but also downstream targets of EphA such as Rho/RAS-related genes (e.g., RASD1, ARHGAP, and RGNEF); this is significant findings. Activation of these proteins in various cell lines and carcinoma cells regulates cell-cell interactions through modulation of integrin activity and cell survival pathways [52-54], suggesting that they may perform a similar function in hBMSCs. Regulation of integrin activity has been demonstrated to be a key mechanism underpinning the effects of the ephrin and Eph system on cell-matrix adhesion and migration. For example, ephrin-A signaling activates the integrin pathway, thereby increasing cell adhesion or changing cell morphology and motility [55-57]. EphA-ephrin-A binding also induces integrin clustering for cell segregation during development [58]. Therefore, the EphA5 downregulation induced by DEX may be associated with ITGA5 upregulation [16] to increase osteoblast differentiation and osteogenesis in vitro. In the present study, EphA5 overexpression in hBMSCs decreased not only ITGA5 mRNA levels but also cell attachment to collagen I. This unclear mechanism for the adhesive effects should be fully explored; however, it might be partially involved in the ITGA5 level, which is supposed to be associated with cell adhesion and apoptosis according to the previous report [16]. We previously confirmed that population-selective effects of DEX enhanced the differentiation of BMSCs [14]. However, we did not characterize the selected cells or the mechanism of how they were selected in detail. Notably, we have also confirmed the osteogenic differentiation effects of DEX using immortalized human
BMSCs, which are considered to be a single-cell-derived and homogenous population because they have been passaged numerous times (data not published). Studies using homogenous cell populations may depict a process different from our proposed mechanism of cell subpopulation selection by competitive proliferation.

As an alternative to subpopulation selection, we also observed that DEX augmented the responsiveness of hBMSCs to osteogenic stimulation by BMP in the previous study. In particular, DEX treatment promptly augmented BMPinduced phosphorylation of SMAD1/5/8 within $24 \mathrm{~h}$ but only scarcely affected the cell subpopulation distribution in the same time period [15]. DEX treatment also inhibited EphA5 mRNA expression by 6 hours, which was associated with increased levels of ALP in the present study. This rapid decrease in EphA5 levels suggests that DEX mediates a phenotypic switch from senescence to rapid growth in hBMSCs through targeting of this dormancy-associated marker EphA5, in addition to the previously observed subpopulation redistribution effect. The decrease in EphA5 levels may contribute to amelioration of cell senescence and to higher cell responsiveness to differentiation-inducing factors. Considering that not only repeating passages but also BMP-2 treatment induced EphA5 expression to some degree, this result seems to indicate that EphA5 is also a differentiation marker rather than a senescence-related marker. But first, there were times when BMP-2 treatment did not increase ALP expression on hBMSCs under certain conditions such as at low density (Figure 2(d)) or in some samples due to the individual responsiveness. Secondly, we have demonstrated that BMP2 treatment could promote osteogenic differentiations of hBMSCs in a different manner, maintaining or promoting the overall expression profile of ephrins and Eph receptors whereas DEX treatment could have selective effects on ephrin/Eph subfamilies in hBMSCs. We speculate that BMP could upregulate other ephrin/Eph subfamilies or accelerate other ways of signaling which could have stronger effects than those of EphA5, leading to osteogenic differentiation despite increased EphA5 levels. Due to these strong and global effects of BMP-2 with an overall upregulation of many molecules, we think that EphA5 should not be regarded as a differentiation marker even if it could be increased by BMP2. We observed that DEX treatment selectively inhibited not only mRNA expression of EphA5 but also EphA2, which was also known as an osteogenic inhibitor $[7,23]$, while DEX increased the levels of osteogenic stimulators such as ephrinB2 [6] and EphA4 [8]. Apart from the effect of one of wellestablished osteogenic induction reagents, BMP-2, we have focused on the unclear and selective effect of DEX which could suppress osteogenic inhibitors in this paper. Further experiments must be needed to investigate the association between BMP signaling and ephrin/Eph subfamilies, and the mechanism of a synergetic effect of DEX and BMP-2.

Several studies have provided evidence that EphA5 is frequently downregulated in various cancer cell lines and tumor tissues via aberrant hypermethylation of its promoter $[32,34]$. However, the nature of the stimulus that upregulates EphA5 over repeated passaging in BMSCs remains unclear. We indicated that histone deacetylation might be associated with 
the observed upregulation of EphA5. As one of limitations to our study, this VPA experiment is a global stimulus and the effect cannot be assigned to EphA5. Histone $\mathrm{H} 3$ acetylation at Lys9 and Lys14 (H3K9K14ac) or trimethylation at Lys9 and Lys27 (H3K9me3 and H3K27me3) in general correlates with open or closed chromatin state $[59,60]$. We need to investigate posttranslational modification of histone $\mathrm{H} 3$ bound to the EphA5 promoters using chromatin immunoprecipitation (ChIP). Recently, miR-34a was reported to negatively modulate chondrogenesis by targeting EphA5 in chick limb mesenchymal cells [61], whereas antiangiogenic and dormancy-promoting molecules including EphA5 were reported to be upregulated by expression of dormancyassociated miR-580, miR-588, and miR-190 [37]. Further studies are thus required to determine the particular stimulus leading to upregulation of EphA5 over repeated passaging, including the potential role of miRNA.

In summary, in repeatedly passaged cultures, the upregulation of dormancy-associated EphA5 independent of methylation may inhibit signaling by other EphA or EphB family members through direct interactions, although competition for ligand binding may also occur. An imbalance between EphA5 and ligand expression may compromise Eph liganddependent differentiation processes (Figure 5) and may mediate ligand-independent processes in hBMSCs. Elucidation of the potential inhibitory function of EphA5 expressed in hBMSCs may provide an alternative approach for manipulating the fate of hBMSCs and for lineage differentiation in cell therapy strategies and regenerative medicine.

\section{Conflict of Interests}

The authors declare that there is no conflict of interests regarding the publication of this paper.

\section{Acknowledgments}

The authors gratefully thank Tetsuya Jinno, MD, and Daisuke Koga, MD, for the collection of bone marrow aspirates during the operation procedure; Ryuta Sakuma, Ph.D., for help with lentivirus production; and Yusuke Hirabayashi, Ph.D., for valuable suggestions. This work was supported by a Grantin-Aid for Scientific Research from the Japan Society for the Promotion of Science.

\section{References}

[1] M. F. Pittenger, A. M. Mackay, S. C. Beck et al., "Multilineage potential of adult human mesenchymal stem cells," Science, vol. 284, no. 5411, pp. 143-147, 1999.

[2] D. J. Prockop, "Marrow stromal cells as stem cells for nonhematopoietic tissues," Science, vol. 276, no. 5309, pp. 71-74, 1997.

[3] V. Vacanti, E. Kong, G. Suzuki, K. Sato, J. M. Canty, and T. Lee, "Phenotypic changes of adult porcine mesenchymal stem cells induced by prolonged passaging in culture," Journal of Cellular Physiology, vol. 205, no. 2, pp. 194-201, 2005.
[4] W. Wagner, P. Horn, M. Castoldi et al., "Replicative senescence of mesenchymal stem cells: a continuous and organized process," PLoS ONE, vol. 3, no. 5, Article ID e2213, 2008.

[5] T. Yamada, M. Yuasa, T. Masaoka et al., "After repeated division, bone marrow stromal cells express inhibitory factors with osteogenic capabilities, and EphA5 is a primary candidate," Bone, vol. 57, no. 2, pp. 343-354, 2013.

[6] C. Zhao, N. Irie, Y. Takada et al., "Bidirectional ephrinB2-EphB4 signaling controls bone homeostasis," Cell Metabolism, vol. 4, no. 2, pp. 111-121, 2006.

[7] N. Irie, Y. Takada, Y. Watanabe et al., "Bidirectional signaling through EphrinA2-EphA2 enhances osteoclastogenesis and suppresses osteoblastogenesis," The Journal of Biological Chemistry, vol. 284, no. 21, pp. 14637-14644, 2009.

[8] V. Stiffel, M. Amoui, M. H.-C. Sheng, S. Mohan, and K.-H. W. $\mathrm{Lau}$, "EphA4 receptor is a novel negative regulator of osteoclast activity," Journal of Bone and Mineral Research, vol. 29, no. 4, pp. 804-819, 2014.

[9] S. Tanabe, Y. Sato, T. Suzuki, K. Suzuki, T. Nagao, and T. Yamaguchi, "Gene expression profiling of human mesenchymal stem cells for identification of novel markers in early- and latestage cell culture," Journal of Biochemistry, vol. 144, no. 3, pp. 399-408, 2008.

[10] A. Derfoul, G. L. Perkins, D. J. Hall, and R. S. Tuan, "Glucocorticoids promote chondrogenic differentiation of adult human mesenchymal stem cells by enhancing expression of cartilage extracellular matrix genes," Stem Cells, vol. 24, no. 6, pp. 14871495, 2006.

[11] N. Indrawattana, G. Chen, M. Tadokoro et al., "Growth factor combination for chondrogenic induction from human mesenchymal stem cell," Biochemical and Biophysical Research Communications, vol. 320, no. 3, pp. 914-919, 2004.

[12] I. Sekiya, D. C. Colter, and D. J. Prockop, "BMP-6 enhances chondrogenesis in a subpopulation of human marrow stromal cells," Biochemical and Biophysical Research Communications, vol. 284, no. 2, pp. 411-418, 2001.

[13] N. Jaiswal, S. E. Haynesworth, A. I. Caplan, and S. P. Bruder, "Osteogenic differentiation of purified, culture-expanded human mesenchymal stem cells in vitro," Journal of Cellular Biochemistry, vol. 64, no. 2, pp. 295-312, 1997.

[14] H. Oshina, S. Sotome, T. Yoshii et al., "Effects of continuous dexamethasone treatment on differentiation capabilities of bone marrow-derived mesenchymal cells," Bone, vol. 41, no. 4, pp. 575-583, 2007.

[15] M. Yuasa, T. Yamada, T. Taniyama et al., "Dexamethasone enhances osteogenic differentiation of bone marrow-and musclederived stromal cells and augments ectopic bone formation induced by bone morphogenetic protein-2," PLOS ONE, vol. 10, no. 2, Article ID 0116462, 2015.

[16] Z. Hamidouche, O. Fromigué, J. Ringe et al., "Priming integrin $\alpha 5$ promotes human mesenchymal stromal cell osteoblast differentiation and osteogenesis," Proceedings of the National Academy of Sciences of the United States of America, vol. 106, no. 44, pp. 18587-18591, 2009.

[17] Y. Akaneya, K. Sohya, A. Kitamura et al., "Ephrin-A5 and EphA5 interaction induces synaptogenesis during early hippocampal development," PLoS ONE, vol. 5, no. 8, Article ID e12486, 2010.

[18] N. M. Abdul-Aziz, M. Turmaine, N. D. E. Greene, and A. J. Copp, "EphrinA-EphA receptor interactions in mouse spinal neurulation: implications for neural fold fusion," International Journal of Developmental Biology, vol. 53, no. 4, pp. 559-568, 2009. 
[19] Y. Hara, T. Nomura, K. Yoshizaki, J. Frisén, and N. Osumi, "Impaired hippocampal neurogenesis and vascular formation in Ephrin-A5-deficient mice," Stem Cells, vol. 28, no. 6, pp. 974983, 2010.

[20] J. Holmberg, A. Armulik, K.-A. Senti et al., "Ephrin-A2 reverse signaling negatively regulates neural progenitor proliferation and neurogenesis," Genes and Development, vol. 19, no. 4, pp. 462-471, 2005.

[21] M. R. Hornberger, D. Dütting, T. Ciossek et al., "Modulation of EphA receptor function by coexpressed ephrinA ligands on retinal ganglion cell axons," Neuron, vol. 22, no. 4, pp. 731-742, 1999.

[22] G. Zimmer, B. Kästner, F. Weth, and J. Bolz, "Multiple effects of ephrin-A5 on cortical neurons are mediated by Src family kinases," The Journal of Neuroscience, vol. 27, no. 21, pp. 56435653, 2007.

[23] H. Miao, E. Burnett, M. Kinch, E. Simon, and B. Wang, "Activation of EphA2 kinase suppresses integrin function and causes focal-adhesion-kinase dephosphorylation," Nature Cell Biology, vol. 2, no. 2, pp. 62-69, 2000.

[24] M. J. Ting, B. W. Day, M. D. Spanevello, and A. W. Boyd, "Activation of ephrin A proteins influences hematopoietic stem cell adhesion and trafficking patterns," Experimental Hematology, vol. 38, no. 11, pp. 1087-1098, 2010.

[25] M. Tanaka, R. Kamata, and R. Sakai, "EphA2 phosphorylates the cytoplasmic tail of claudin-4 and mediates paracellular permeability," Journal of Biological Chemistry, vol. 280, no. 51, pp. 42375-42382, 2005.

[26] N. W. Gale, S. J. Holland, D. M. Valenzuela et al., "Eph receptors and ligands comprise two major specificity subclasses and are reciprocally compartmentalized during embryogenesis," Neuron, vol. 17, no. 1, pp. 9-19, 1996.

[27] A. M. Flenniken, N. W. Gale, G. D. Yancopoulos, and D. G. Wilkinson, "Distinct and overlapping expression patterns of ligands for eph-related receptor tyrosine kinases during mouse embryogenesis," Developmental Biology, vol. 179, no. 2, pp. 382401, 1996.

[28] H. U. Wang, Z.-F. Chen, and D. J. Anderson, "Molecular distinction and angiogenic interaction between embryonic arteries and veins revealed by ephrin-B2 and its receptor Eph-B4," Cell, vol. 93, no. 5, pp. 741-753, 1998.

[29] S. M. Alam, J. Fujimoto, I. Jahan, E. Sato, and T. Tamaya, "Coexpression of EphB4 and ephrinB2 in tumour advancement of ovarian cancers," British Journal of Cancer, vol. 98, no. 4, pp. 845-851, 2008.

[30] J. W. Astin, J. Batson, S. Kadir et al., "Competition amongst Eph receptors regulates contact inhibition of locomotion and invasiveness in prostate cancer cells," Nature Cell Biology, vol. 12, no. 12, pp. 1194-1204, 2010.

[31] Y. Dong, J. Wang, Z. Sheng et al., "Downregulation of EphA1 in colorectal carcinomas correlates with invasion and metastasis," Modern Pathology, vol. 22, no. 1, pp. 151-160, 2009.

[32] D.-Y. Fu, Z.-M. Wang, B.-L. Wang et al., "Frequent epigenetic inactivation of the receptor tyrosine kinase EphA5 by promoter methylation in human breast cancer," Human Pathology, vol. 41, no. 1 , pp. $48-58,2010$.

[33] N. I. Herath and A. W. Boyd, "The role of Eph receptors and ephrin ligands in colorectal cancer," International Journal of Cancer, vol. 126, no. 9, pp. 2003-2011, 2010.

[34] S. Li, Y. Zhu, C. Ma et al., "Downregulation of EphA5 by promoter methylation in human prostate cancer," BMC Cancer, vol. 15, no. 1, article 18, 2015.
[35] B. Wang, "Cancer cells exploit the eph-ephrin system to promote invasion and metastasis: tales of unwitting partners," Science Signaling, vol. 4, article pe28, 2011.

[36] N. Almog, L. Ma, R. Raychowdhury et al., "Transcriptional switch of dormant tumors to fast-growing angiogenic phenotype," Cancer Research, vol. 69, no. 3, pp. 836-844, 2009.

[37] N. Almog, L. Ma, C. Schwager et al., "Consensus micro RNAs governing the switch of dormant tumors to the fast-growing angiogenic phenotype," PLoS ONE, vol. 7, no. 8, Article ID e44001, 2012.

[38] Y. Ning, J. L. Weber, A. M. Killary, D. H. Ledbetter, J. R. Smith, and O. M. Pereira-Smith, "Genetic analysis of indefinite division in human cells: evidence for a cell senescence-related gene(s) on human chromosome 4," Proceedings of the National Academy of Sciences of the United States of America, vol. 88, no. 13, pp. 56355639, 1991.

[39] E. B. Pasquale, "Eph receptor signalling casts a wide net on cell behaviour," Nature Reviews Molecular Cell Biology, vol. 6, no. 6, pp. 462-475, 2005.

[40] E. B. Pasquale, "Eph receptors and ephrins in cancer: bidirectional signalling and beyond," Nature Reviews Cancer, vol. 10, no. 3, pp. 165-180, 2010.

[41] D. Schmucker and S. L. Zipursky, "Signaling downstream of Eph receptors and ephrin ligands," Cell, vol. 105, no. 6, pp. 701-704, 2001.

[42] R. F. Carvalho, M. Beutler, K. J. M. Marler et al., "Silencing of EphA3 through a cis interaction with ephrinA5," Nature Neuroscience, vol. 9, no. 3, pp. 322-330, 2006.

[43] T. Marquardt, R. Shirasaki, S. Ghosh et al., "Coexpressed EphA receptors and ephrin-A ligands mediate opposing actions on growth cone navigation from distinct membrane domains," Cell, vol. 121, no. 1, pp. 127-139, 2005.

[44] E. Nievergall, M. Lackmann, and P. W. Janes, "Eph-dependent cell-cell adhesion and segregation in development and cancer," Cellular and Molecular Life Sciences, vol. 69, no. 11, pp. 1813$1842,2012$.

[45] H. Miao and B. Wang, "EphA receptor signaling-complexity and emerging themes," Seminars in Cell \& Developmental Biology, vol. 23, no. 1, pp. 16-25, 2012.

[46] G. R. Mundy and F. Elefteriou, "Boning up on ephrin signaling," Cell, vol. 126, no. 3, pp. 441-443, 2006.

[47] A. Arthur, A. Zannettino, R. Panagopoulos et al., "EphB/ephrin$B$ interactions mediate human MSC attachment, migration and osteochondral differentiation," Bone, vol. 48, no. 3, pp. 533-542, 2011.

[48] N. K. Noren, N.-Y. Yang, M. Silldorf, R. Mutyala, and E. B. Pasquale, "Ephrin-independent regulation of cell substrate adhesion by the EphB4 receptor," Biochemical Journal, vol. 422, no. 3, pp. 433-442, 2009.

[49] A. Freywald, N. Sharfe, and C. M. Roifman, "The kinase-null EphB6 receptor undergoes transphosphorylation in a complex with EphB1," The Journal of Biological Chemistry, vol. 277, no. 6, pp. 3823-3828, 2002.

[50] C. Gu and S. Park, “The EphA8 receptor regulates integrin activity through p110 $\gamma$ phosphatidylinositol-3 kinase in a tyrosine kinase activity-independent manner," Molecular and Cellular Biology, vol. 21, no. 14, pp. 4579-4597, 2001.

[51] H. Miao, K. Strebhardt, E. B. Pasquale, T.-L. Shen, J.-L. Guan, and B. Wang, "Inhibition of integrin-mediated cell adhesion but not directional cell migration requires catalytic activity of EphB3 receptor tyrosine kinase. Role of RHO family small 
GTPases," The Journal of Biological Chemistry, vol. 280, no. 2, pp. 923-932, 2005.

[52] H. L. Holen, M. Shadidi, K. Narvhus, O. Kjøsnes, A. Tierens, and H.-C. Aasheim, "Signaling through ephrin-A ligand leads to activation of Src-family kinases, Akt phosphorylation, and inhibition of antigen receptor-induced apoptosis," Journal of Leukocyte Biology, vol. 84, no. 4, pp. 1183-1191, 2008.

[53] M. Aoki, T. Yamashita, and M. Tohyama, "EphA receptors direct the differentiation of mammalian neural precursor cells through a mitogen-activated protein kinase-dependent pathway," The Journal of Biological Chemistry, vol. 279, no. 31, pp. 32643-32650, 2004.

[54] K. K. Murai and E. B. Pasquale, "'Eph'ective signaling: forward, reverse and crosstalk," Journal of Cell Science, vol. 116, no. 14, pp. 2823-2832, 2003.

[55] J. Huai and U. Drescher, "An ephrin-A-dependent signaling pathway controls integrin function and is linked to the tyrosine phosphorylation of a $120-\mathrm{kDa}$ protein," The Journal of Biological Chemistry, vol. 276, no. 9, pp. 6689-6694, 2001.

[56] N. Sharfe, M. Nikolic, L. Cimpeon, A. Van De Kratts, A. Freywald, and C. M. Roifman, "EphA and ephrin-A proteins regulate integrin-mediated T lymphocyte interactions," Molecular Immunology, vol. 45, no. 5, pp. 1208-1220, 2008.

[57] T. Yamazaki, J. Masuda, T. Omori, R. Usui, H. Akiyama, and Y. Maru, "EphAl interacts with integrin-linked kinase and regulates cell morphology and motility," Journal of Cell Science, vol. 122, no. 2, pp. 243-255, 2009.

[58] D. Jülich, A. P. Mould, E. Koper, and S. A. Holley, "Control of extracellular matrix assembly along tissue boundaries via integrin and Eph/Ephrin signaling," Development, vol. 136, no. 17, pp. 2913-2921, 2009.

[59] S. L. Berger, "Histone modifications in transcriptional regulation," Current Opinion in Genetics and Development, vol. 12, no. 2, pp. 142-148, 2002.

[60] R. Cao and Y. Zhang, "The functions of E(Z)/EZH2-mediated methylation of lysine 27 in histone H3," Current Opinion in Genetics \& Development, vol. 14, no. 2, pp. 155-164, 2004.

[61] D. Kim, J. Song, S. Kim, C. H. Chun, and E. J. Jin, "MicroRNA34 a regulates migration of chondroblast and IL- $1 \beta$-induced degeneration of chondrocytes by targeting EphA5," Biochemical and Biophysical Research Communications, vol. 415, no. 4, pp. 551-557, 2011. 

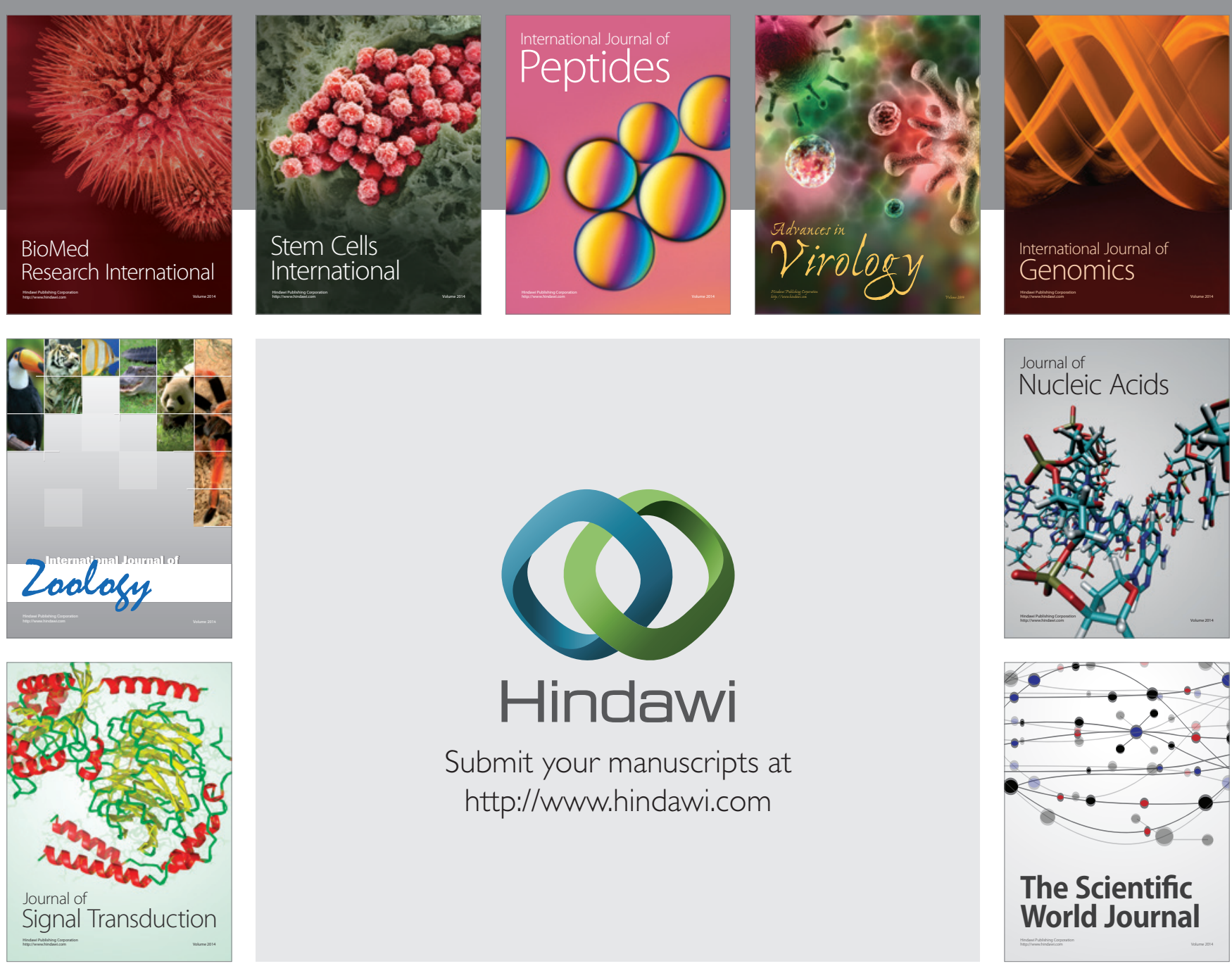

Submit your manuscripts at

http://www.hindawi.com
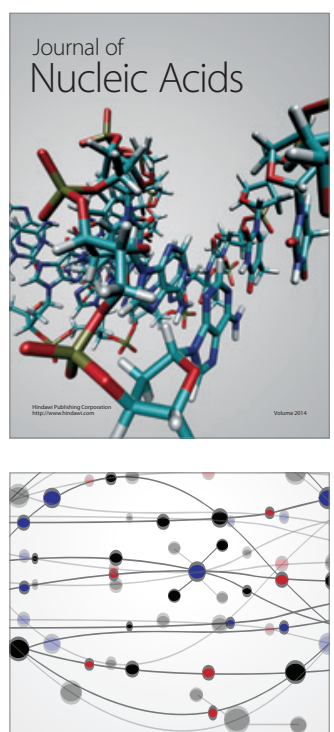

The Scientific World Journal
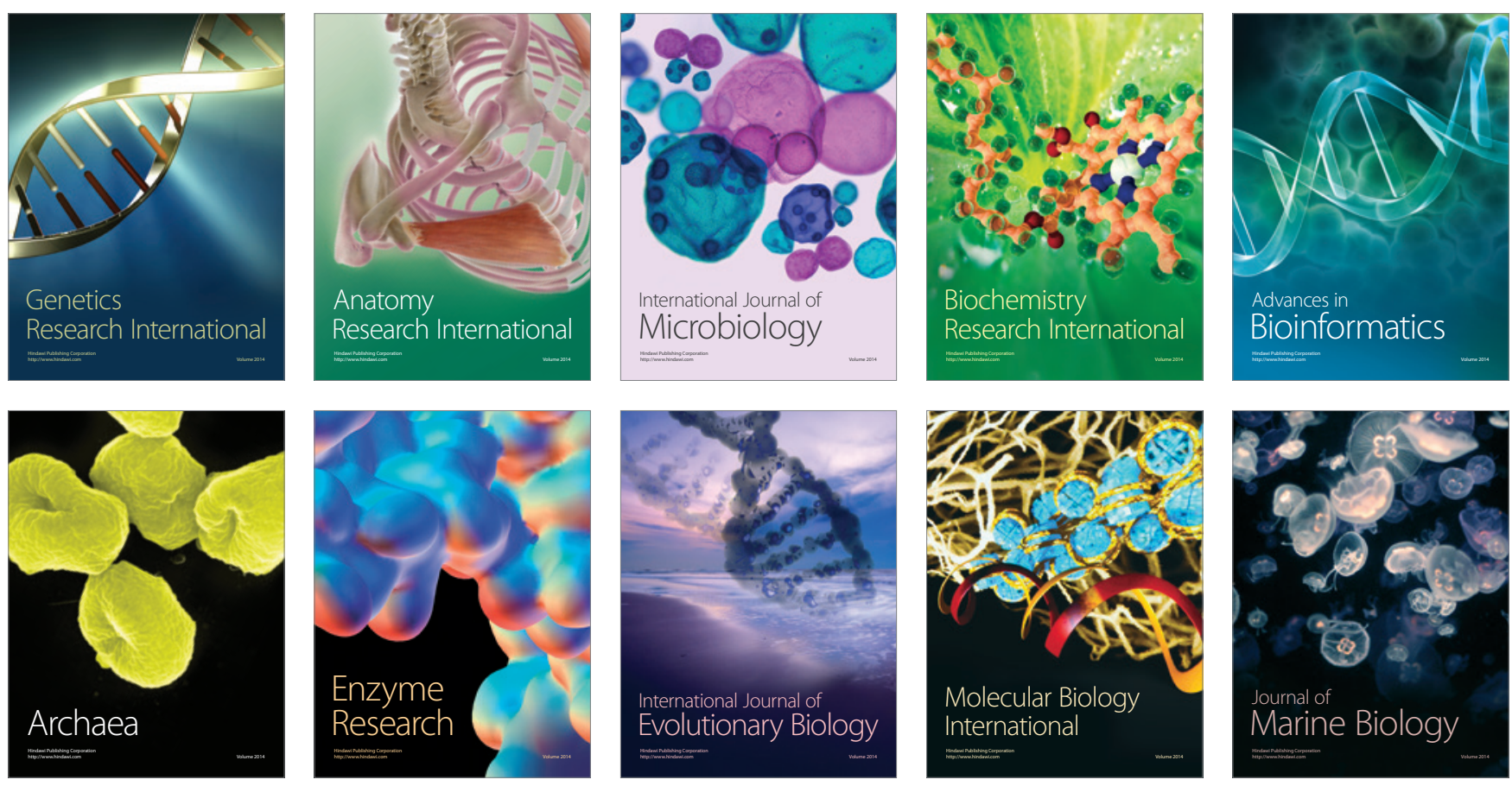